\title{
The influence of multiple tubes on the tube-to-bed heat transfer in a fluidised bed
}

\author{
L.M. Armstrong, S. Gu*, K.H. Luo \\ Energy Technology Research Group, School of Engineering Sciences, University of Southampton, Southampton SO17 1BJ, United Kingdom
}

\section{A R T I C L E I N F O}

\section{Article history:}

Received 23 March 2010

Received in revised form 11 June 2010

Accepted 24 July 2010

Available online 19 August 2010

\section{Keywords:}

CFD

Heat transfer

Fluidised bed

Eulerian

\begin{abstract}
A B S T R A C T
There have been few studies modelling both flow and heat transfer in fluidised beds. The kinetic theory of granular flow (KTGF) has been used for flow prediction in the past without heat transfer modelling. In the present study, a two-fluid Eulerian-Eulerian formulation incorporating the KTGF was applied first to a tube-to-bed reactor with one immersed tube and compared with the results in the literature. The bed was then modified to introduce two and three heated tubes. The effects on the flow and temperature distribution, local heat transfer coefficients and averaged heat transfer coefficients over a $3.0 \mathrm{~s}$ time period were carried out. Results showed that increasing the number of tubes promotes heat transfer from tubes to the particles and flow. The heat transfer coefficients extracted from the single-tube to three-tube cases were analysed in detail, confirming the importance of linking flow/particle and heat transfer calculations.
\end{abstract}

(c) 2010 Elsevier Ltd. All rights reserved.

\section{Introduction}

Computational fluid dynamics (CFD) has become a viable tool for simulating the dynamic processes that take place in fluidised beds. The greatly increased computer performance and capabilities nowadays allow non-linear thermal-fluid dynamics in complex geometries under realistic conditions to be investigated in a non-invasive manner. Numerous studies on the isothermal hydrodynamics of fluidised bed reactors have been carried out to understand the complex interactions between gas and particles (Berruti et al., 1995; Ge and Li, 2003; Samuelsberg and Hjertager, 1995; Benyahia et al., 2000; Almuttahar and Taghipour, 2008; Goldschmidt et al., 2001; Armstrong et al., 2009, 2010a). Computational modelling of heattransfer in bubbling fluidised beds has also been performed (Kuipers et al., 1992; Schmidt and Renz, 1999, 2000; Patil et al., 2006; Armstrong et al., 2010b,c). However, these models tend to show a strong over-prediction of the local heat-transfer coefficient compared to experimental data. The Eulerian-Eulerian two-fluid model (TFM) is the most frequently applied method for modelling hydrodynamics (Samuelsberg and Hjertager, 1995; Benyahia et al., 2000; Almuttahar and Taghipour, 2008, 2009; Sundaresan, 2000) and heat transfer (Patil et al., 2006; Schmidt and Renz, 1999, 2000; Kuipers et al., 1992) within fluidised beds. The model assumes that the gas and solid phases as continuous and fully interpenetrating within each control volume. It is less computationally exhaustive in comparison to the other models: the discrete Eulerian-Lagrangian method which simulates the individual particle dynamics (Gera

\footnotetext{
* Corresponding author. Tel.: +44 238059 4760; fax: +44 2380593058 .

E-mail address: s.gu@soton.ac.uk (S.Gu).
}

et al., 1998, 2004; Ibsen et al., 2004), and the complete Lagrangian approach which models both particle and fluid phases within a Lagrangian framework (Ge and Li, 2003, 1997, 2001). The interaction of individual lagrangian particles with an Eulerian-Eulerian fluidised bed has also been carried out (Papadikis et al., 2008, 2009a,b,c,d, 2010a,,,). However, the TFM has issues with regard to scaling up in sizes of fluidised beds to be simulated. In order to obtain sufficient information about particle-fluid interactions and structures, small control volumes are required, which makes it expensive to simulate large systems (although using EulerianLagrangian, or full Lagrangian would be even more expensive). Particularly when heat transfer modelling is included, extremely small control volumes are needed to account for the presence of a thermal boundary layer whose thickness is of the order of a particle diameter (Schmidt and Renz, 2000; Kuipers et al., 1992).

The drag models are important in simulating the interphase momentum transfer between the gas and particle phases. The drag force occurs due to the differences in velocity between the phases and is a function of the Reynolds number and the solid volume fraction. Therefore the drag force in dilute regions differs greatly from that in dense phases. The Gidaspow et al. (1992) and Syamlal and O'Brien (1987) models were developed to accommodate both dilute and dense regions in the bed whereas there are models developed for either dilute (Wen and Yu, 1966) or dense (Ergun, 1952) phases. The Gidaspow model is a combination of the Wen and Yu (1966) model for dilute phases and the Ergun (1952) model for dense phases whereas the Syamlal-O'Brien model was developed on the basis of measurement of the terminal velocities of particles in fluidised beds. Other drag models include those of Arastoopour et al. (1990) and Di Felice (1994). Although these models have performed reasonably, they are classified as empirical 
models because they were derived from the analysis of experimental data. In contrast, Hill et al. (2001a,b) applied the LatticeBoltzmann method (LBM) to a collection of dispersed particles fixed in space for different solids volume fractions and Reynolds numbers. A drag model was constructed, which is kinetic-based, as LBM is built upon kinetic theory. Their work was later extended to cover the full range of Reynolds numbers and volume fractions, which allows for application to TFM models as well (Benyahia et al., 2006). Although there have been extensive comparisons of drag models in hydrodynamics (Taghipour et al., 2005), to the author's knowledge parallel work has not been carried out within heat transfer modelling of fluidised beds.

The kinetic theory of granular flow (KTGF) is widely used for modelling the motion of particles. The basic concept of KTGF is the granular temperature. During random oscillations of the particles, inelastic collisions occur causing energy to be dissipated. The granular temperature measures these random oscillations of the particles and is defined as the average of the three variances of the particle's velocities. A full mathematical description of the kinetic theory is provided by Gidaspow (1994). Patil et al. (2006) carried out a comparison of KTGF with another set of closure equations for the solid-phase rheology, namely the constant viscosity model (CVM). The latter assumed the particle viscosity was constant and the particle pressure was a function of the porosity of the local solid using empirical correlations. The results found that in a wall-to-bed fluidised case, the KTGF correctly predicted the passage of the bubble whereas the CVM showed the bubble would move away from the wall too early.

The thermal conductivities of the two phases are treated with separate models instead of the overall bulk thermal conductivity (Kuipers et al., 1992; Syamlal and Gidaspow, 1985). This is because Zehner and Schlünder (1970) proposed that the thermal conductivities were a function of volume fraction, solid material and gaseous properties. The effective solid thermal conductivity was later ex- pressed in terms of the internal molecular conductivity and the particle kinetic conductivity (Natarajan and Hunt, 1998). Kinetic conductivity models have been carried out previously (Schmidt and Renz, 2000; Patil et al., 2006; Hunt, 1997) however, Patil et al. (2006) found that the high granular temperatures against the wall possibly resulted in a strongly over-predicted kinetic contribution to the effective solid-phase thermal conductivity.

The present work carries out Eulerian-Eulerian modelling for a tube-to-bed heated fluidised bed. The original set-up (Schmidt and Renz, 1999) is modelled and the simulation is extended over a longer period of time than the previous simulation to study the asymmetric dynamics. A number of drag models are tested to determine their influences on the flow. The local temperature distributions at varying distances from the tubes are considered. Furthermore, additional tubes are included in the simulation to determine the effects on flow characteristics, temperature and heat transfer coefficients.

\section{CFD Modelling}

\subsection{Governing equations}

The Eulerian-granular model in FLUENT 6.3.26 was used to model the interactions between gas and granular particles within the aforementioned fluidised bed. This model allows for the presence of two different phases in one control volume of the grid by introducing the volume fraction variable, $\varepsilon_{i}$. The solid phase contains spherical granular particles of the same diameter. These two phases are solved individually using the mass and momentum equations. Table 1 gives details of the full equations. The conservation of energy considers the heat transfer within each phase and the exchange of heat between different phases. Each phase has a separate enthalpy equation and determined by the specific

Table 1

Governing equations.

\begin{tabular}{|c|c|}
\hline Conservation of mass & Eqn. \\
\hline Gas: $\frac{\partial\left(\varepsilon_{g} \rho_{g}\right)}{\partial t}+\nabla \cdot\left(\varepsilon_{g} \rho_{g} \vec{v}_{g}\right)=0$ & $(10)$ \\
\hline Particles: $\frac{\partial\left(\varepsilon_{s} \rho_{s}\right)}{\partial t}+\nabla \cdot\left(\varepsilon_{s} \rho_{s} \vec{v}_{s}\right)=0$ & $(11)$ \\
\hline \multicolumn{2}{|l|}{ Conservation of momentum } \\
\hline Gas: $\quad \frac{\partial\left(\varepsilon_{g} \rho_{g} \vec{v}_{g}\right)}{\partial t}+\nabla \cdot\left(\varepsilon_{g} \rho_{g}\left(\vec{v}_{g} \otimes \vec{v}_{g}\right)\right)=-\varepsilon_{g} \nabla p+\nabla \cdot \overline{\bar{\tau}}_{g}+\varepsilon_{g} \rho_{g} \vec{g}+K_{g s}\left(\vec{v}_{g}-\vec{v}_{s}\right)$ & $(12)$ \\
\hline Particles: $\frac{\partial\left(\varepsilon_{s} \rho_{s} \vec{v}_{s}\right)}{\partial t}+\nabla \cdot\left(\varepsilon_{s} \rho_{s}\left(\vec{v}_{s} \otimes \vec{v}_{s}\right)\right)=-\varepsilon_{s} \nabla p-\nabla p_{s}+\nabla \cdot \overline{\bar{\tau}}_{s}+\varepsilon_{s} \rho_{g} \vec{g}+K_{g s}\left(\vec{v}_{g}-\vec{v}_{s}\right)$ & $(13)$ \\
\hline Phase stress-strain tensor: $\quad \overline{\bar{\tau}}_{q}=\varepsilon_{q} \mu_{q}\left(\nabla \vec{v}_{q}+\nabla \vec{v}_{q}^{T}\right)+\varepsilon_{q}\left(\lambda_{q}-\frac{2}{3} \mu_{q}\right) \nabla \cdot \vec{v}_{q} \overline{\bar{I}}_{q}$ & $(14)$ \\
\hline \multicolumn{2}{|l|}{ Conservation of energy } \\
\hline Gas: $\quad \frac{\partial}{\partial t}\left(\varepsilon_{g} \rho_{g} H_{g}\right)+\nabla \cdot\left(\varepsilon_{g} \rho_{g} \vec{v}_{g} H_{g}\right)=\nabla \cdot \varepsilon_{g} \kappa_{g}^{\text {eff }} \nabla T_{g}-h_{g s}\left(T_{s}-T_{q}\right)$ & $(15)$ \\
\hline Particles: $\quad \frac{\partial}{\partial t}\left(\varepsilon_{s} \rho_{s} H_{s}\right)+\nabla \cdot\left(\varepsilon_{s} \rho_{s} \vec{v}_{s} H_{s}\right)=\nabla \cdot \varepsilon_{s} \kappa_{s}^{e f f} \nabla T_{s}+h_{s g}\left(T_{s}-T_{g}\right)$ & $(16)$ \\
\hline \multicolumn{2}{|l|}{ Drag models } \\
\hline$K_{g s}=150 \frac{\varepsilon_{s}^{2} \mu_{g}}{\varepsilon_{g} d_{s}^{2}}+1.75 \frac{\varepsilon_{s} \rho_{g}\left|\vec{v}_{s}-\vec{v}_{g}\right|}{d_{s}} \quad$ for $\varepsilon_{g} \leqslant 0.8$ & $(17)$ \\
\hline$K_{g s}=\frac{3}{4} C_{D} \frac{\varepsilon_{s} \varepsilon_{g} \rho_{g}\left|\vec{s}_{s}-\vec{\nabla}_{g}\right|}{d_{s}} \varepsilon_{g}^{-2.65}$ for $\varepsilon_{g}>0.8$ & $(18)$ \\
\hline$C_{D}=\frac{24}{\varepsilon_{g} R_{s}}\left[1+0.15\left(\varepsilon_{g} R e_{s}\right)^{0.687}\right]$ & $(19)$ \\
\hline \multicolumn{2}{|l|}{ Syamlal-O’Brien drag model } \\
\hline$K_{g s}=\frac{3}{4} \frac{\varepsilon_{s} \varepsilon_{g} \rho_{g}}{V_{t s}^{2} d_{s}} C_{D}\left(\frac{R e_{s}}{v_{r s}}\right)\left|\vec{v}_{s}-\vec{v}_{g}\right|$ & (20) \\
\hline$C_{D}=\left(0.63+\frac{4.8}{\sqrt{\operatorname{Re}_{s} V_{r, s}}}\right)^{2}$ & $(21)$ \\
\hline$v_{r, s}=0.5\left(A-0.06 R e_{s}+\sqrt{\left(0.06 R e_{s}\right)^{2}+0.12 R e_{s}(2 B-A)+A^{2}}\right)$ & (22) \\
\hline$A=\varepsilon_{g}^{4.14} \quad B=\varepsilon_{g}^{2.65} \quad$ for $\varepsilon_{g}>0.85$ & \\
\hline$A=\varepsilon_{g}^{4.14} \quad B=0.8 \varepsilon_{g}^{1.28} \quad$ for $\varepsilon_{g} \leqslant 0.85$ & \\
\hline \multicolumn{2}{|l|}{ Arastoopour drag model } \\
\hline$K_{g s}=\left[\frac{17.3}{R e_{s}}+0.336\right] \frac{\rho_{g}}{d_{s}}\left|\vec{v}_{s}-\vec{v}_{g}\right| \alpha_{s} \alpha_{g}^{-2.8}$ & $(23)$ \\
\hline
\end{tabular}


Table 2

Drag models.

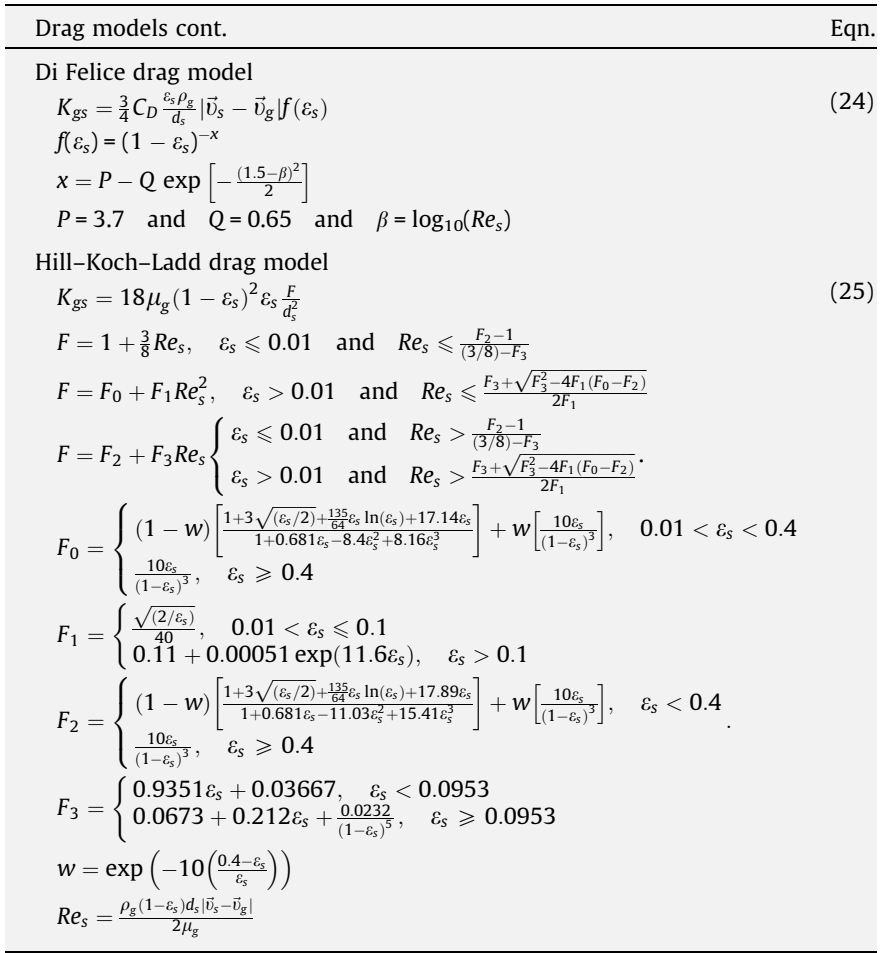

enthalpy, $H(\mathrm{~J} / \mathrm{kg})$, the mixture thermal conductivity, $\kappa_{i}$, and the heat exchange between the gas and solid phases, $h_{g s}$. The gas-solid interphase exchange coefficient, $K_{g s}$, was modelled using the Arastoopour et al. (1990), Di Felice (1994), Gidaspow et al. (1992), modified drag correlation of (Benyahia et al., 2006) and the Syamlal and O'Brien (1987) drag models shown in Table 1. The different drag coefficients, $C_{D}$, are given in Table 2 . The kinetic fluctuations between particles were considered using the kinetic theory of granular flow given in Table 3 to find the granular temperature, $\Theta\left(\mathrm{m}^{2} / \mathrm{s}^{2}\right)$. The equation for the kinetic fluctuation of energy also considers the transfer of kinetic energy, $\phi\left(\mathrm{kg} / \mathrm{s}^{3} \mathrm{~m}\right)$, the collisional dissipation of energy, $\gamma_{i}\left(\mathrm{~kg} / \mathrm{s}^{3} \mathrm{~m}\right)$ and the diffusion coefficient, $k_{\Theta_{\mathrm{s}}}(\mathrm{kg} / \mathrm{s} \mathrm{m})$. The virtual mass and lift effects are negligible as the lift only affects particles of large diameters and this is not the present case.

The solid shear viscosity, $\mu_{i}(\mathrm{~kg} / \mathrm{s} \mathrm{m})$, is composed of collisional, kinetic and frictional effects. For very dense flows, frictional viscosity is applied due to the volume fraction for the particles approaching closely to the packing limit. The friction created between the particles generates a large amount of stress. Schaeffer's expression (Schaeffer, 1987) is used to model the frictional viscosity in dense cases with an angle of internal friction, $\phi$, of $30^{\circ}$. The bulk viscosity, $\lambda_{i}(\mathrm{~kg} / \mathrm{s} \mathrm{m})$, accounts for the resistance of particles to expansion and depression and is calculated using an expression from Lun et al. (1984). The solids pressure, $p_{i}(\mathrm{~Pa})$ is composed of two terms, where the first term represents the kinetic term and the second term is due to particle collisions (Eq. (37)). It was determined from an equation of state which was similar to the van der Waals equation of state for gases (Chapman and Cowling, 1970). The radial distribution function, $g_{0}$ modifies the probability of particle collisions as the phase becomes dense. Table 3 contains the equations for these constitutive equations.

\subsubsection{Interphase heat transfer}

The heat-transfer coefficient, $\alpha$ is related to the Nusselt number, $N u_{s}$, using the following:

$\alpha=\frac{6 \kappa_{g} \varepsilon_{s} \varepsilon_{g} N u_{s}}{d_{p}^{2}}$

Table 3

Constitutive equations.

\begin{tabular}{|c|c|}
\hline Constitutive equations & Eqn. \\
\hline \multicolumn{2}{|l|}{ Kinetic fluctuation energy } \\
\hline$\frac{3}{2}\left[\frac{\partial}{\partial t}\left(\varepsilon_{s} \rho_{s} \Theta_{s}\right)+\nabla \cdot\left(\varepsilon_{s} \rho_{s} \vec{v}_{s} \Theta_{s}\right)\right]=\left(-p_{s} \cdot \overline{\bar{I}}+\overline{\bar{\tau}}_{s}\right): \nabla \vec{v}_{s}+\nabla \cdot\left(k_{\Theta_{s}} \cdot \nabla \Theta_{s}\right)-\gamma_{\Theta_{s}}+\phi_{g s}$ & $(26)$ \\
\hline$\gamma_{\Theta_{s}}=\frac{12(1-e)^{2} g_{0}}{d_{s} \pi} \varepsilon_{s}^{2} \rho_{s} \Theta_{s}^{3 / 2}$ & $(27)$ \\
\hline$\phi_{g s}=-3 K_{g s} \Theta_{s}$ & $(28)$ \\
\hline \multicolumn{2}{|l|}{ Gidaspow diffusion coefficient } \\
\hline$k_{\Theta_{s}}=\frac{150 \rho_{s} d_{s} \sqrt{\Theta_{s} \pi}}{384(1+e) g_{0}}\left[1+\frac{6}{5} \varepsilon_{s} g_{0}(1+e)\right]^{2}+2 \varepsilon_{s}^{2} \rho_{s} d_{s}(1+e) g_{0} \sqrt{\frac{\Theta_{s}}{\pi}}$ & $(29)$ \\
\hline \multicolumn{2}{|l|}{ Syamlal diffusion coefficient } \\
\hline $\begin{array}{l}k_{\Theta_{s}}=\frac{15 \varepsilon_{s} \rho_{s} d_{s} \sqrt{\theta_{s} \pi}}{4(41-33 \eta)}\left[1+\frac{12}{5} \eta^{2}(4 \eta-3) \varepsilon_{s} g_{0}+\frac{16}{15 \pi}(41-33 \eta) \eta \varepsilon_{s} g_{0}\right] \\
\eta=\frac{1}{2}(1+e)\end{array}$ & $(30)$ \\
\hline Solids shear viscosity: $\mu_{s}=\mu_{s, \text { col }}+\mu_{s, \text { kin }}+\mu_{\text {s,fr }}$ & $(31)$ \\
\hline Collisional viscosity: $\mu_{s, \mathrm{col}}=\frac{4}{5} \varepsilon_{s} d_{s} \rho_{s} g_{0}(1+e)\left(\frac{\Theta_{s}}{\pi}\right)^{1 / 2}$ & $(32)$ \\
\hline Gidaspow kinetic viscosity: $\quad \mu_{s, \text { kin }}=\frac{\varepsilon_{s} d_{s} \rho_{s} \sqrt{\theta_{s} \pi}}{6(3-e)}\left[1+\frac{2}{5} \varepsilon_{s} g_{0}(1+e)(3 e-1)\right]$ & $(33)$ \\
\hline Syamlal kinetic viscosity: $\quad \mu_{s, \text { kin }}=\frac{10 d_{s} \rho_{s} \sqrt{\theta_{s} \pi}}{96_{s} g_{0}(1+e)}\left[1+\frac{4}{5} \varepsilon_{s} g_{0}(1+e)\right]^{2}$ & $(34)$ \\
\hline Frictional viscosity: $\quad \mu_{s, \mathrm{fr}}=\frac{p_{s} \sin \phi}{2 \sqrt{l_{2 D}}}$ & $(35)$ \\
\hline Solid bulk viscosity: $\quad \lambda_{s}=\frac{4}{3} \varepsilon_{s} d_{s} \rho_{s} g_{0}(1+e)\left(\frac{\Theta_{s}}{\pi}\right)^{1 / 2}$ & $(36)$ \\
\hline Particle pressure: $p_{s}=\varepsilon_{s} \rho_{s} \Theta_{s}+2 \rho_{s}(1+e) \varepsilon_{s}^{2} g_{0} \Theta_{s}$ & $(37)$ \\
\hline Radial distribution function: $g_{0}=\left[1-\left(\frac{\varepsilon_{s}}{\varepsilon_{s \max }}\right)^{1 / 3}\right]^{-1}$ & $(38)$ \\
\hline \multicolumn{2}{|l|}{ Particle phase boundary conditions } \\
\hline Velocity: $\quad \vec{u}_{s, w}=-\frac{6 \mu_{s} \varepsilon_{s, m a x}}{\sqrt{3} \sqrt{\theta} \pi \rho_{s} \varepsilon_{s} g_{0}} \frac{\partial \vec{s}_{s, w}}{\partial n}$ & (39) \\
\hline \multicolumn{2}{|l|}{ Granular temperature: } \\
\hline 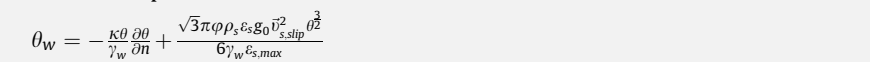 & $(40)$ \\
\hline$\gamma_{w}=\frac{\sqrt{3} \pi\left(1-e_{w}^{2}\right) \varepsilon_{s} \rho_{s} g_{0} \theta^{\frac{3}{2}}}{4 \varepsilon_{s, \max }}$ & $(41)$ \\
\hline
\end{tabular}


(a)

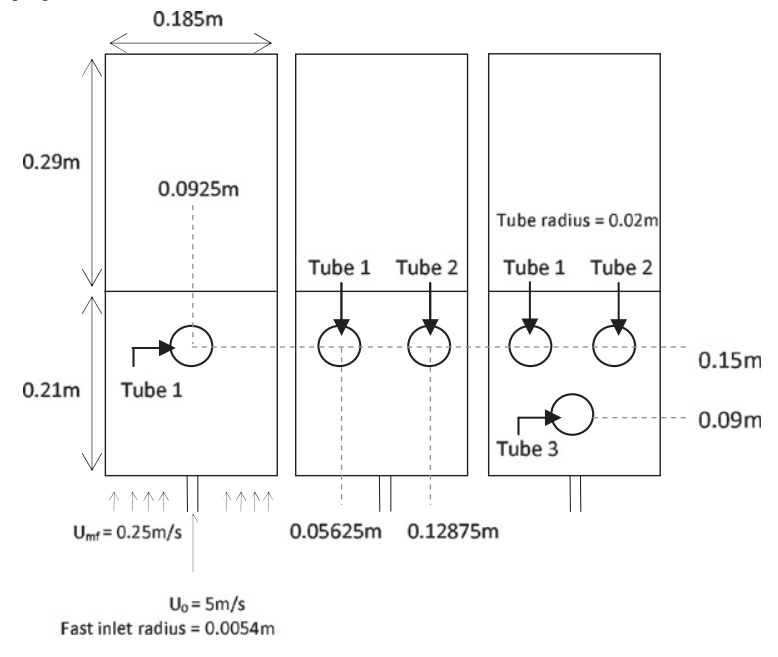

(b)

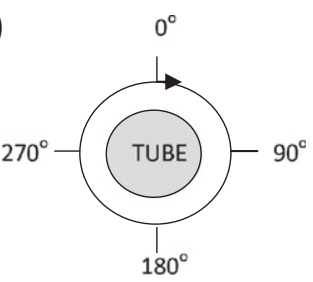

(c)

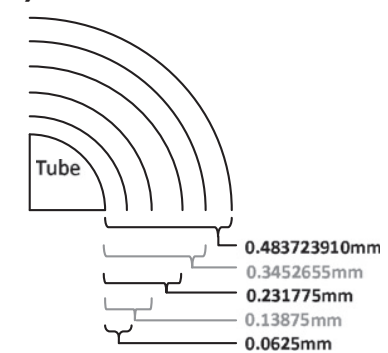

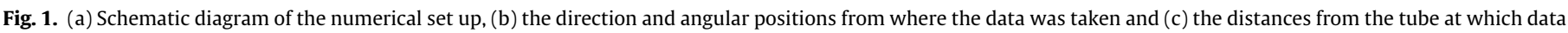
was taken.

An empirical relation for the interphase heat transfer coefficient was proposed by Gunn (1978) which relates the Nusselt number with the particle Reynolds, $R e_{p}$ and Prandtl numbers, $\operatorname{Pr}$ :

$$
\begin{aligned}
N u_{s}= & \left(7-10 \varepsilon_{g}+5 \varepsilon_{g}^{2}\right)\left[1+0.7\left(\operatorname{Re}_{p}\right)^{0.2}(\operatorname{Pr})^{1 / 3}\right] \\
& +\left(1.33-2.40 \varepsilon_{g}+1.20 \varepsilon_{g}^{2}\right)\left(\operatorname{Re}_{p}\right)^{0.2}(\operatorname{Pr})^{1 / 3}
\end{aligned}
$$

where:

$\operatorname{Pr}=\frac{C_{p, g} \mu_{g}}{\kappa_{g}}$

\subsubsection{Effective thermal conductivities}

The effective thermal conductivities for each phase are taken from the literature (Kuipers et al., 1992; Patil et al., 2006). The effective thermal conductivity for the gas phase is given by:

$\kappa_{g}^{e f f}=\left(\frac{1-\sqrt{\varepsilon_{s}}}{\varepsilon_{g}}\right) \kappa_{g}$

Natarajan and Hunt (1998) expressed the effective thermal conductivity of the solids phase as the sum of the internal molecular conductivity and the particle kinetic conductivity as follows:

$\kappa_{s}^{e f f}=\kappa_{s}^{m o l}+\kappa_{s}^{k i n}$

Where the molecular contribution is given by:

$\kappa_{s}^{m o l}=\frac{1}{\sqrt{\varepsilon_{s}}} \kappa_{g}[\omega A+(1-\omega) \Gamma]$

where

$\Gamma=\frac{2}{\left(1-\frac{B}{A}\right)}\left[\frac{(A-1)}{\left(1-\frac{B}{A}\right)^{2}} \frac{B}{A} \ln \left(\frac{A}{B}\right)-\frac{(B-1)}{\left(1-\frac{B}{A}\right)}-\frac{B+1}{2}\right]$

$A=\frac{\kappa_{s}}{\kappa_{g}}$

$B=1.25\left(\frac{\varepsilon_{s}}{\varepsilon g}\right)^{10 / 9}$ Hunt (1997) derived the following equation for the $\omega=7.26 \times 10^{-3}$

kinetic contribution:

$\kappa_{s}^{k i n}=\rho_{s} C_{p} d_{p} \sqrt{\Theta_{s}} \frac{\pi^{3 / 2}}{32 g_{o}}$

\subsection{Model set-up}

A two-dimensional numerical model is set up based on that of Schmidt and Renz (1999). Three gas fluidised bed reactors were modelled with one, two and three horizontal heated immersed tubes as displayed in Fig. 1a. Glass bead particles were used with a uniform diameter of $500 \mu \mathrm{m}$ and density $2660 \mathrm{~kg} / \mathrm{m}^{3}$ whilst the fluidising gas was air with a density of $1.225 \mathrm{~kg} / \mathrm{m}^{3}$ and viscosity of $1.79 \times 10^{-5} \mathrm{~kg} / \mathrm{m} \mathrm{s}$. Two air velocities were induced: a fast air inflow at the centre of the reactor base to produce air bubbles and a slow velocity distributed over the rest of the reactor base. Both inlet velocities match those of the previous model by Schmidt and Renz (1999). The fast air inlet has a velocity $5 \mathrm{~m} / \mathrm{s}$ whilst the slow inlet is set to the minimum fluidising velocity, $0.25 \mathrm{~m} / \mathrm{s}$. The immersed tubes are set to a constant wall temperature, $T$, of $373 \mathrm{~K}$ whilst the remaining reactor walls are assumed adiabatic and the initial bed temperature was set to $293 \mathrm{~K}$. The boundary conditions for gas phase along the wall is set to a no-slip condition whereas the particles are allowed to slip down the wall using the boundary conditions derived by Sinclair and Jackson (1989). The equations for the boundary conditions and the parameters used are given in Tables 3 and 4, respectively.

Table 4

Table of parameters.

\begin{tabular}{llll}
\hline Gas & & & Units \\
\hline$v_{g}$ & Fast inlet velocity & 5 & $\mathrm{~m} / \mathrm{s}$ \\
$v_{m f}$ & Slow inlet velocity & 0.25 & $\mathrm{~m} / \mathrm{s}$ \\
$\rho_{g}$ & Density & 1.225 & $\mathrm{~kg} / \mathrm{m}^{3}$ \\
$\mu_{g}$ & Shear viscosity & $1.79 \times 10^{-5}$ & $\mathrm{~kg} / \mathrm{m} \mathrm{s}$ \\
$C_{p, g}$ & Specific heat & 994 & $\mathrm{~J} / \mathrm{kg} \mathrm{K}$ \\
$\kappa_{g}$ & Thermal conductivity & 0.0257 & $\mathrm{~W} / \mathrm{K} \mathrm{m}$ \\
$P a r t i c l e s$ & & & \\
$d_{p}$ & Particle diameter & 500 & $\mu \mathrm{m}$ \\
$\rho_{p}$ & Particle density & 2660 & $\mathrm{~kg} / \mathrm{m}^{3}$ \\
$C_{p, p}$ & Specific heat & 737 & $\mathrm{~J} / \mathrm{kg} \mathrm{K}$ \\
$\kappa_{p}$ & Thermal conductivity & 1.0 & $\mathrm{~W} / \mathrm{K} \mathrm{m}$ \\
$e$ & Particle coef. of restitution & 0.95 & \\
$e_{w}$ & Wall coef. of restitution & 0.9 & \\
$\varphi$ & Specularity coefficient & 0.25 & \\
\hline
\end{tabular}




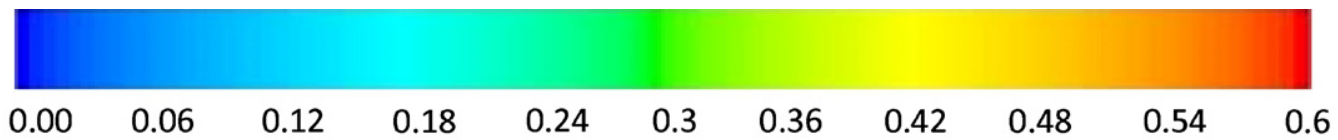

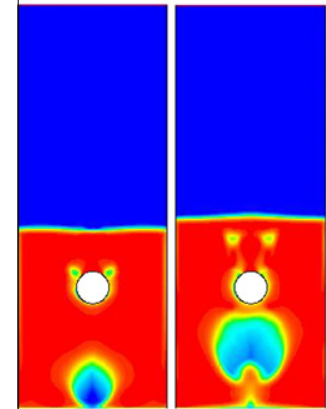

$0.1 \mathrm{~s}$

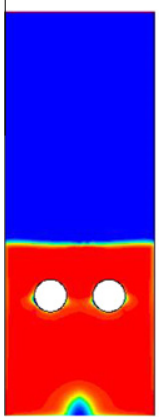

$0.1 \mathrm{~s}$

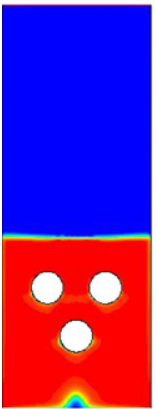

$0.1 \mathrm{~s}$

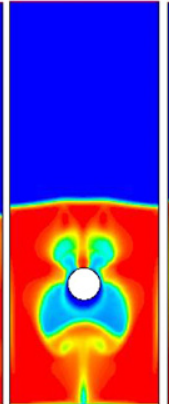

$0.3 \mathrm{~s}$

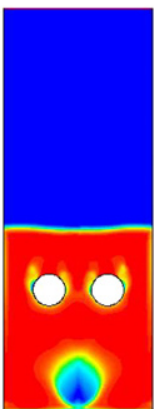

$0.2 \mathrm{~s}$

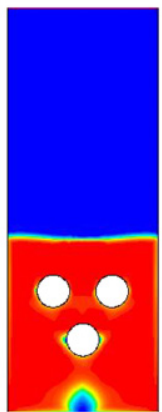

$0.2 \mathrm{~s}$

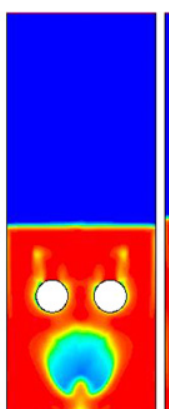

$0.3 \mathrm{~s}$

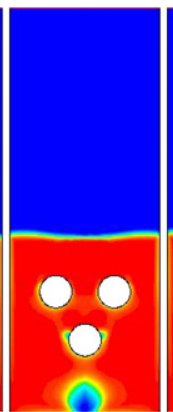

$0.3 \mathrm{~s}$

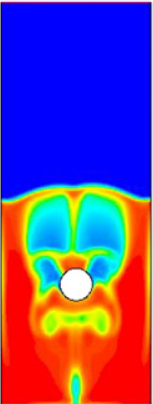

$0.4 \mathrm{~s}$

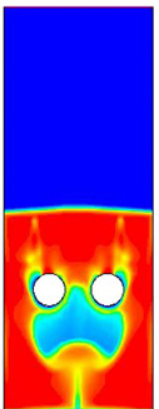

$0.4 \mathrm{~s}$

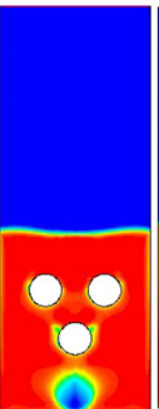

$0.4 \mathrm{~s}$

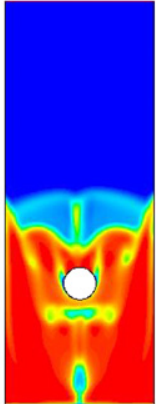

$0.5 \mathrm{~s}$

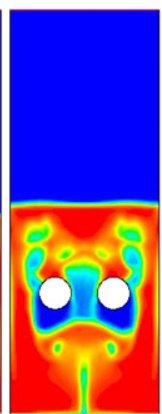

$0.5 \mathrm{~s}$

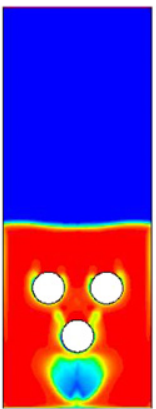

$0.5 \mathrm{~s}$

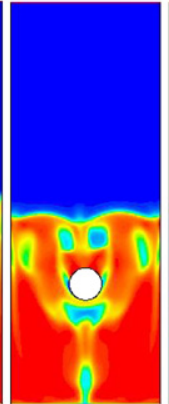

$0.6 \mathrm{~s}$

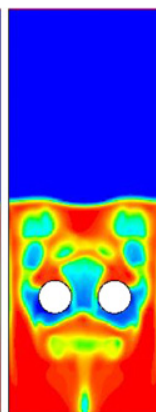

$0.6 \mathrm{~s}$

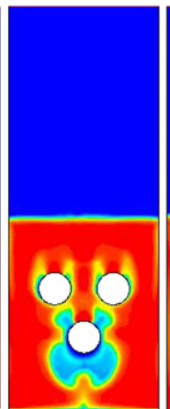

$0.6 \mathrm{~s}$

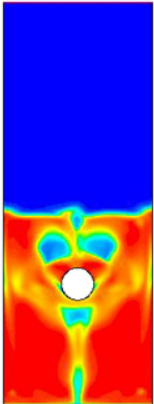

$0.7 \mathrm{~s}$

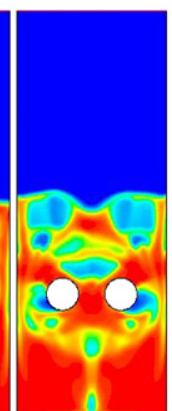

$0.7 \mathrm{~s}$

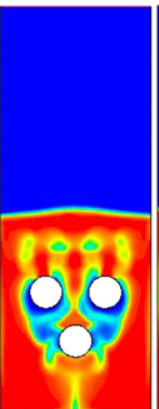

$0.7 \mathrm{~s}$

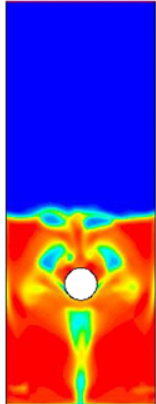

$0.8 \mathrm{~s}$

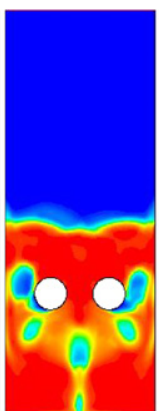

$0.8 \mathrm{~s}$

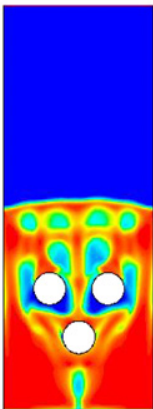

$0.8 \mathrm{~s}$

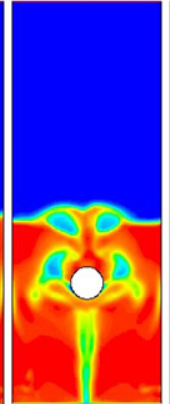

$0.9 \mathrm{~s}$

$1.0 \mathrm{~s}$

Fig. 2. Contour plots of the particle volume fractions over the initial $1.0 \mathrm{~s}$ using the Gidaspow drag model.

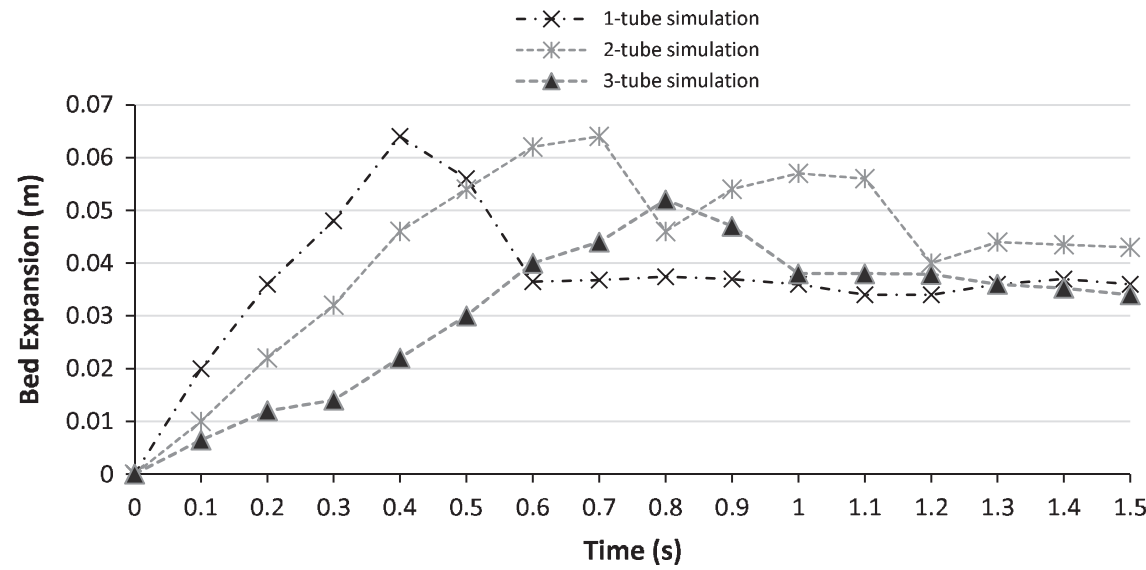

Fig. 3. The approximate bed expansion for all three reactors with increasing time using the Gidaspow drag model. 
A mesh was created using 30,704 quadrilateral cells for the 1-tube simulation, 32,770 for the 2-tube simulation and 34,922 cells for the 3-tube simulation. The cells near the tubes and walls were refined to capture the particle behaviours in those near-wall regions. The maximum cell size was $0.002 \mathrm{~m}$ and the minimum set to $0.0000625 \mathrm{~m}$ near the tubes. The minimum cell size represents the initial distance that the results are being extracted. Further distances are considered with distances from the tube increasing with a factor of approximately 1.22 and are given in Fig. 1c. Fig. $1 \mathrm{~b}$ displays the direction and angular positions where the data was taken.

The finite volume method was used to solve the governing equations. The coupling and correction of the velocity and pressure is carried out for multiphase flows with the Phase Coupled SIMPLE (PCSIMPLE) algorithm (Vasquez and Ivanov, 2000). The discretisation of the convective terms was carried out with the second-order upwind scheme. A time step of $2.5 \times 10^{-4} \mathrm{~s}$ was used to ensure quick convergence with a maximum of 100 iterations per time step. The convergence criterion between two iterations was set to $1 \times 10^{-3}$

\section{Results}

\subsection{Flow characteristics}

The contour plots of the particle volume fractions within the three reactors are displayed for the first $1.0 \mathrm{~s}$ in Fig. 2 using the Gidaspow drag model. The 1-tube simulation results agree really well with the simulated and experimental results provided in the literature (Schmidt and Renz, 1999). In the early stages of the single immersed tube model a collection of air below the tube forms. A larger air bubble from the inlet ascends through the bed with time whilst the small air voidage under the tube continues up blanketing round the tube. At $0.3 \mathrm{~s}$, this small voidage separates from the tube to continue up through the bed whilst the larger bubble from the inlet reaches the tube and begins to encase the tube. As expected, the presence of large bubbles within the bed causes a higher bed height expansion which is seen in Fig. 2 at $0.3-0.5 \mathrm{~s}$.

Similar trends are seen with the 2-tube and 3-tube simulations however, with each addition of a tube there is a delay of the dynamic processes involved since a longer period of time is required for the blanketing of gas below each tube to build up and for coalescence to take place. Furthermore, Fig. 2 also shows that for a reactor with a tube position directly above the fast air inlet the bubble sizes appear to be smaller. This is particularly seen in the 3-tube simulation as the tubes breaks up the bubbles. This prevents the coalescence of large bubbles resulting in a low bed height expansion. The approximate bed expansion was determined for the three reactors and are shown in Fig. 3. Once the bed dynamics have been established these small bubbles continue with similar sizes resulting in very little variation in bed height.

The 2-tube simulation behaves slightly differently compared to the 1-tube and 3-tube simulations. The bed expansion peaks a number of times around $0.7 \mathrm{~s}, 1.0 \mathrm{~s}$ and $1.4 \mathrm{~s}$. This is seen in Fig. 4 which displays the volume fraction contour plots of the 2 -tube simulations over a longer period. A voidage region lies in the mid-region below the two tubes. As this region expands and the bubbles enlarge they come into contact with the tubes on the outer faces nearer the walls and the gas follows this route though the bed. As the bubbles expand further and rise they form larger bubbles than those seen in the 1-tube and 3-tube simulations which results in an increase in bed height.

The release of a bubble from around each tube appears to alternate between the left and right tube. This is due to the flow

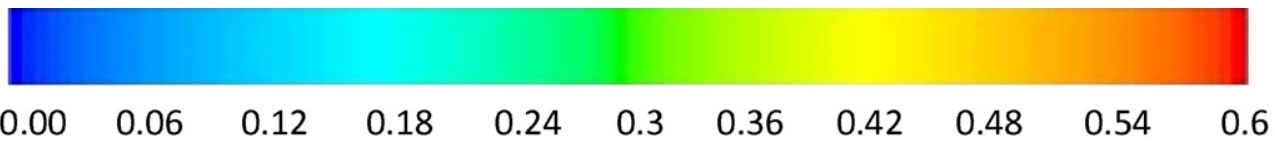

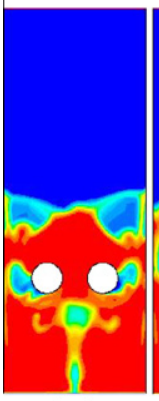

$1.1 \mathrm{~s}$
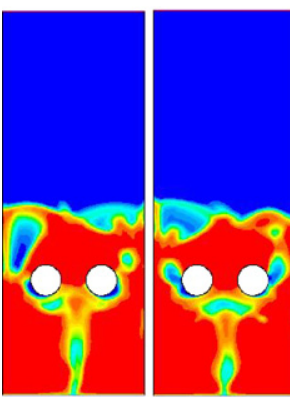

$2.1 \mathrm{~s}$

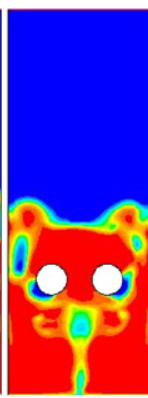

$1.2 \mathrm{~s}$

$2.2 \mathrm{~s}$

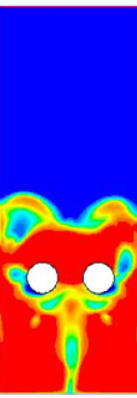

$1.3 \mathrm{~s}$

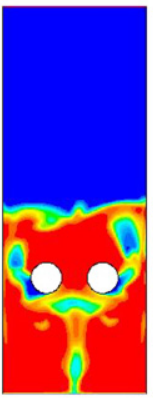

$1.4 \mathrm{~s}$

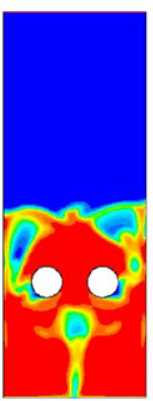

$1.5 \mathrm{~s}$

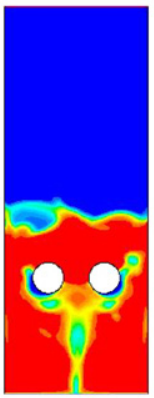

$1.6 \mathrm{~s}$

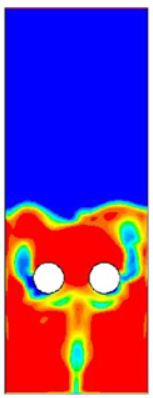

$1.7 \mathrm{~s}$

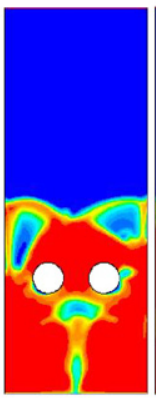

$1.8 \mathrm{~s}$

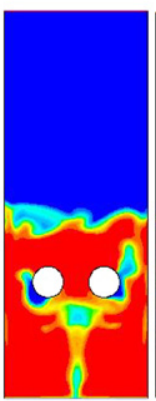

$1.9 \mathrm{~s}$

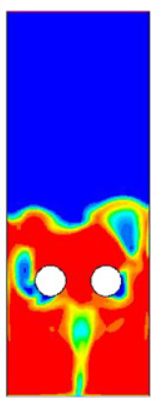

2.0s

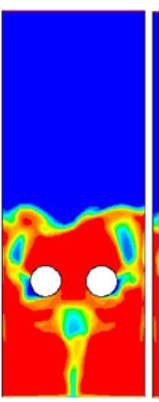

$2.3 \mathrm{~s}$

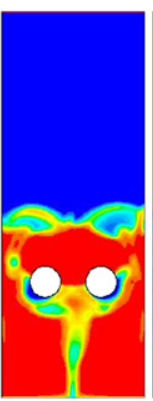

$2.4 \mathrm{~s}$

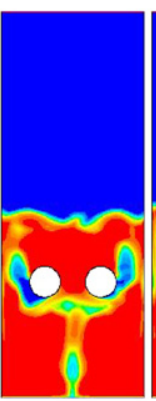

$2.5 \mathrm{~s}$

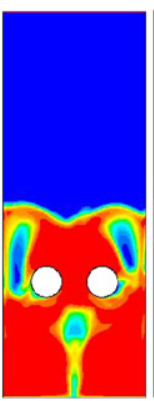

$2.6 s$

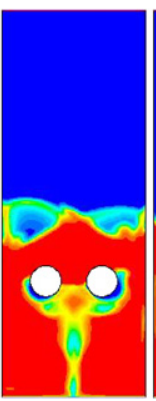

$2.7 \mathrm{~s}$

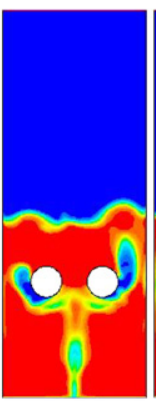

$2.8 \mathrm{~s}$

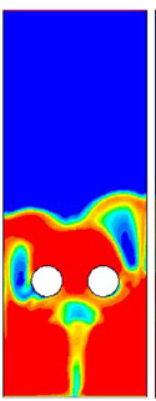

$2.9 s$

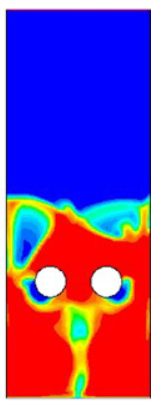

$3.0 \mathrm{~s}$

Fig. 4. Contour plots of the particle volume fractions for the 2-tube simulation over the 1.1-3.0 s period using the Gidaspow drag model. 
dynamics, as a large bubble on the left is formed then the particles in the bed are forced towards the opposite side of the bed suppressing and delaying the bubble formation on the right. This alternating bubble development is a clear indication that the previous model carried by Schmidt and Renz (1999) who applied symmetry by used half the bed for simplicity was not a viable approach. The asymmetry of the bubble locations in the bed can be seen as early as $1.0 \mathrm{~s}$ for all three cases in Fig. 2 thus further confirming the previous assumption by Schmidt and Renz (1999) that a symmetrical model would not capture the full flow characteristics.

\subsection{Local heat transfer coefficients}

The local heat transfer coefficients were taken close to the tube within the reactor of the 1-tube simulation at $0.3 \mathrm{~s}$ where the release of air bubbles from the top of the tube are released back into the bed whilst the larger bubble from the inlet reaches the tube and begins to blanket the tube. As in the previous study (Schmidt and Renz, 1999), the predicted results around the first $180^{\circ}$ in Fig. 5a use the molecular thermal conductivity model only. All the drag models provide similar trends but different magnitudes

(a)

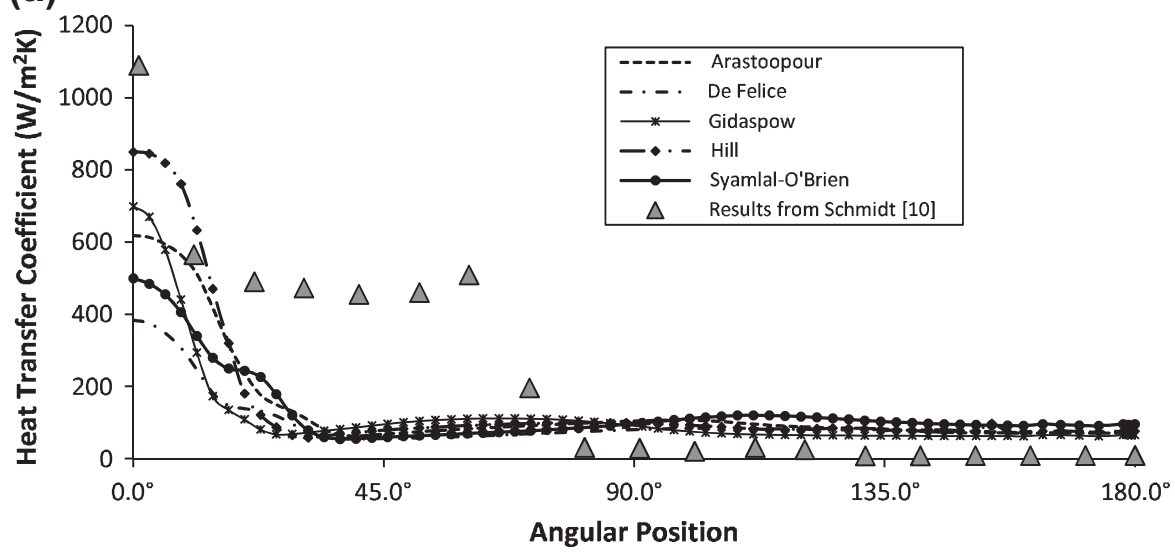

(b)

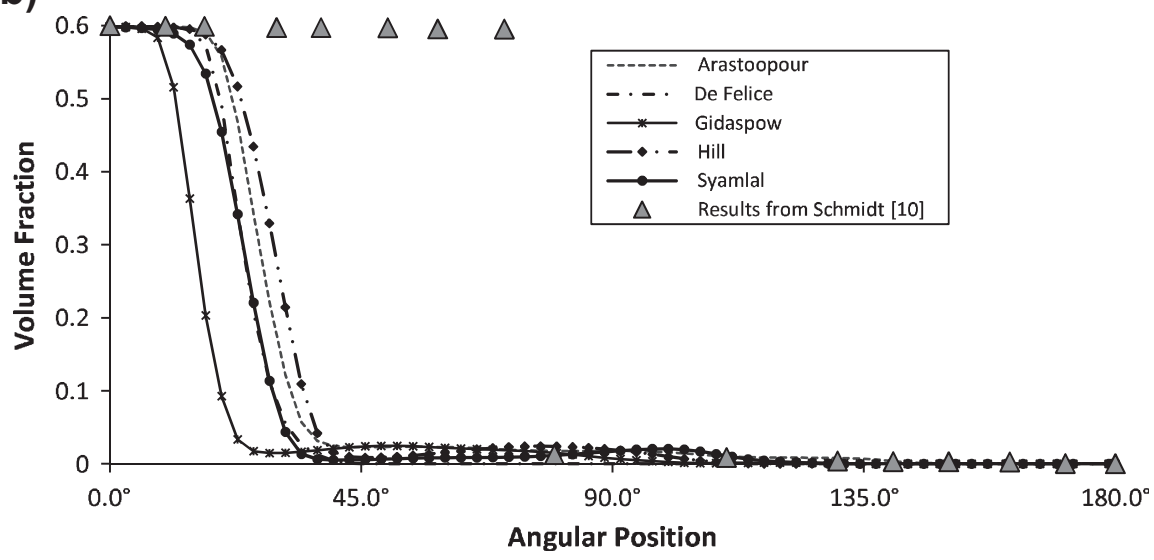

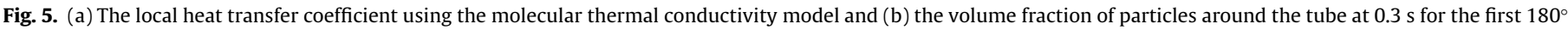
comparing the five drag models and the predicted results from Schmidt and Renz (1999).

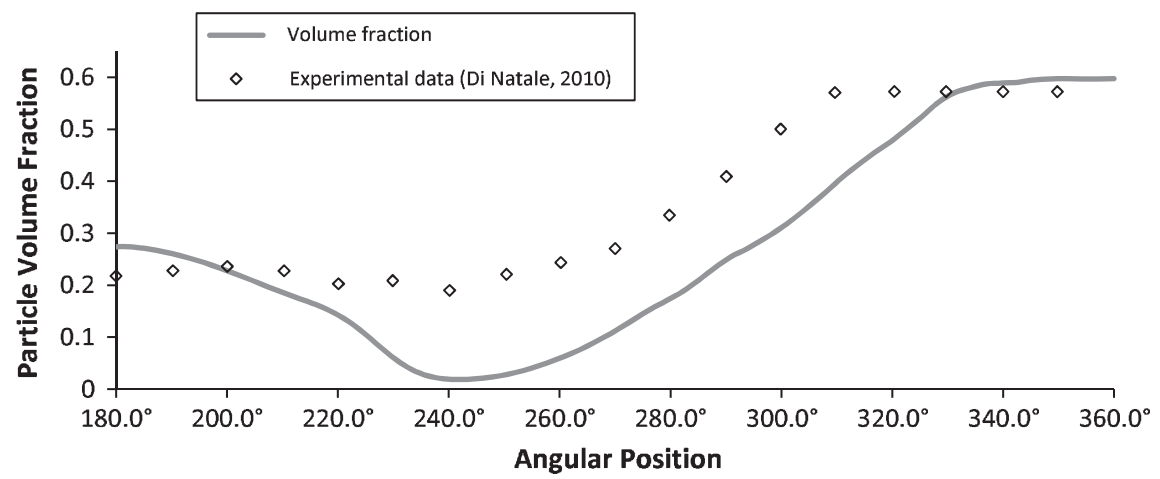

Fig. 6. Time-averaged particle volume fraction compared to experimental results from Di Natale et al. (2010) using the Gidaspow drag model. 
near the tube surfaces. At $0.3 \mathrm{~s}$, the contour plot in Fig. 2 shows a collection of particles above the tube which increases the heat transfer since particles are better conductors than air. This is further displayed in a plot of the volume fraction around the tube in Fig. 5b. As seen previously there is always a region of high volume fraction in contact with the tube so the bubbles do not encase the tube completely (Schmidt and Renz, 1999). There is a difference observed between the simulated results and the predicted results from Schmidt and Renz (1999), particularly between the particle volume fractions. This is because the results are only locally taken and not time-averaged so the variation in the case set up including the complete bed modelling instead of a symmetrical model leads to significant differences at specific local times. This figure shows that as early as $0.3 \mathrm{~s}$ the flow displays a non-symmetrical distribution. The low heat transfer coefficients observed from approximately $30^{\circ}$ occur due to the large air voidage blanketing the tube. Fig. 7 shows the full $360^{\circ}$ results for one tube for the molecular thermal conductivity model only.

Time-averaged particle volume fraction results were taken over a period of $1.0 \mathrm{~s}$ and reported in Fig. 6. The results are compared with the experimental results from Di Natale et al. (2010), who carried out void fraction profiles around a single tube using $500 \mu \mathrm{m}$ glass beads. However, their model was carried out using superficial gas velocities ranging from 0.15 to $0.45 \mathrm{~m} / \mathrm{s}$ which are significantly lower than that used in this case. A similar trend can be seen between the simulation and experimental results although differences are also clearly observed. The values at the lowest and highest point on the tube agree reasonably well with the experimental results. The particle volume fraction around the side of the tube however appears to be significantly lower. This would be due the significantly higher fast inlet velocity of $5.0 \mathrm{~m} / \mathrm{s}$ used compared to $0.45 \mathrm{~m} / \mathrm{s}$ used to obtain the experimental results. The increased velocity could result in the removal of particles around the side of the tube within the vicinity of the tube as the air passes along the tube walls faster. Since the highest point of the tube is seen to have a large collection of particles in contact with the tube this would explain the high particle volume fraction seen both in the simulation and the experiment. This region appears to form later in the simulation due to the increased air velocity continuing around the tube and releasing up in the bed later.

The complete effective thermal conductivity, Eq. (5), was also applied for the five drag models and the results are displayed in Fig. 8. The results show a dramatic increase in the thermal conductivities due to the strong influence the granular temperature has on the kinetic theory of granular flow. The peaks of the heat transfer coefficients do not appear to occur at similar angular positions, indicating that the particle distribution effects are very important and consequently the particle kinetic conductivity is dominant

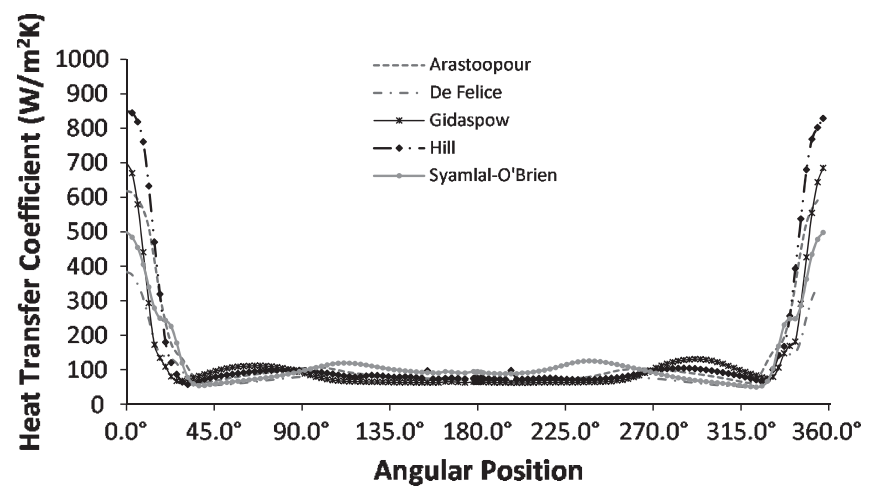

Fig. 7. Local heat transfer coefficient using the molecular thermal conductivity model at $0.3 \mathrm{~s}$ for the full $360^{\circ}$ circumference of the immersed tube comparing the five drag models. over the molecular conductivity. The Syamlal-O'Brien model displays a stronger peak towards the base of the tube which could be due a higher volume fraction of particles there. It should be noted that the Syamlal diffusion coefficient (Eq. (30)) was designed to work with the Syamlal-O'Brien drag model whereas all the other drag models use the standard Gidaspow diffusion coefficient (Eq. (29)) so the use of two different diffusion coefficients within the KTGF could produce significantly different results.

\subsection{Average heat transfer coefficients}

The average heat transfer coefficient extracted from the circumference of the tubes for the three models was taken and plotted

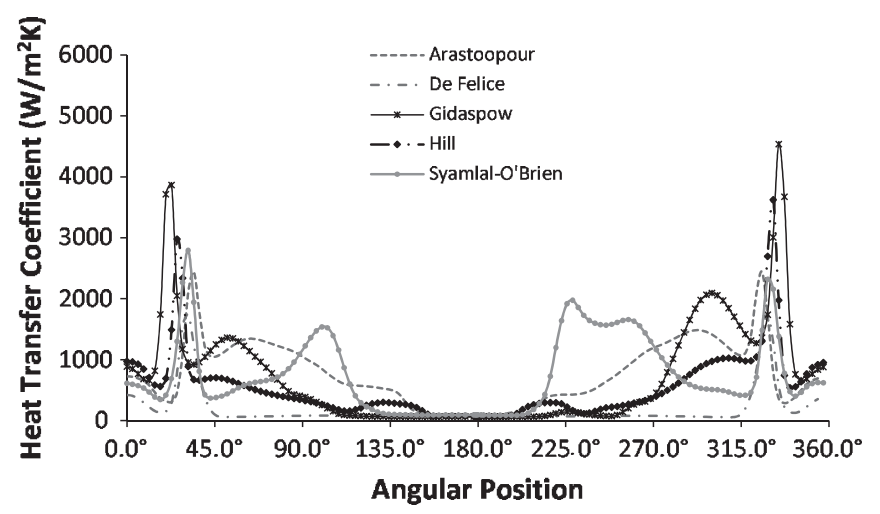

Fig. 8. Local heat transfer coefficient using the complete effective thermal conductivity model at $0.3 \mathrm{~s}$ for the full $360^{\circ}$ circumference of the immersed tube comparing the five drag models.

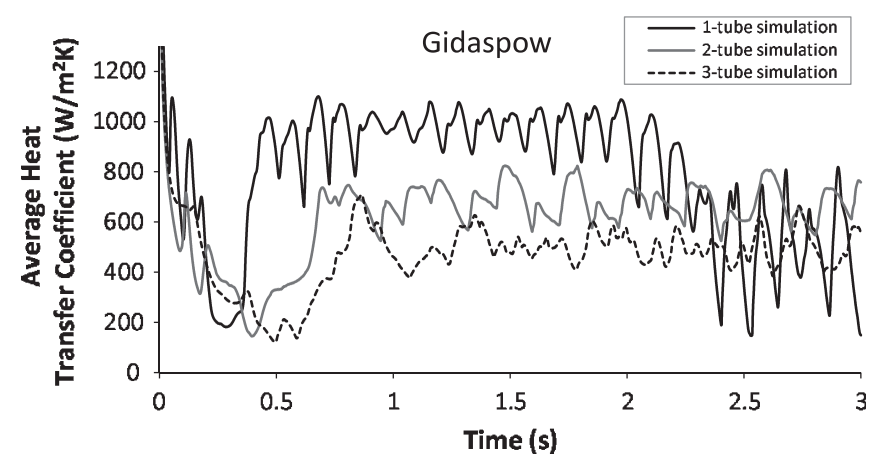

Fig. 9. The average heat transfer coefficients for the three models using the Gidaspow drag models over a period of $3.0 \mathrm{~s}$.

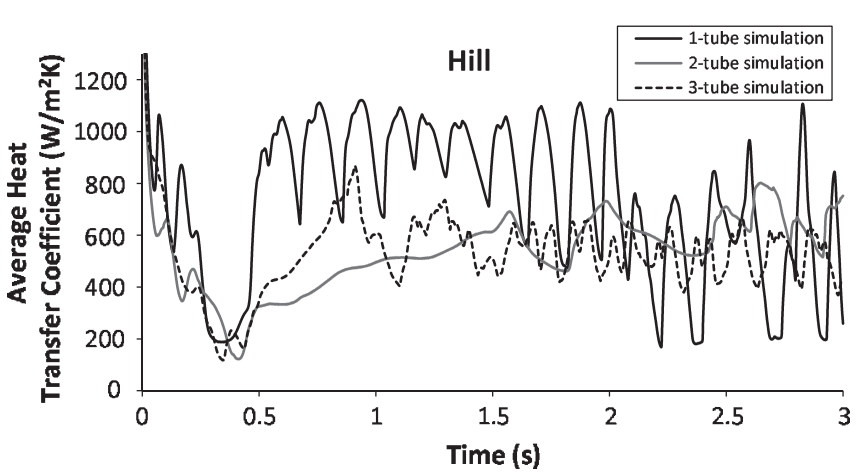

Fig. 10. The average heat transfer coefficients for the three models using the HillKoch-Ladd drag models over a period of $3.0 \mathrm{~s}$. 
over a 3.0 s period for the standard Gidaspow drag model and the modified Hill-Koch-Ladd drag model. These two drag models were chosen to highlight the differences between the standard Gidaspow drag model (Gidaspow et al., 1992) which has been extensively used in the works of hydrodynamic modelling and the recently developed kinetic-based Hill-Koch-Ladd drag model which was derived from Lattice-Boltzman theory (Hill et al., 2001a,b; Benyahia et al., 2006). The average for all the tubes in each model were calculated, namely one tube for the 1-tube simulation, two tubes for the 2-tube simulation and three tubes for the 3-tube simulation. Fig. 9 displays the results of the average heat transfer coefficient predicted by the Gidaspow model. The initially high value of heat transfer coefficient is due to the ideal simulation set up conditions which assumes the bed is set to $293 \mathrm{~K}$. In experimental conditions this would not occur as the wall initially heats up to the constant temperature of $373 \mathrm{~K}$ then the region near the wall heats up with it. Within the first $0.5 \mathrm{~s}$ the average heat transfer coefficients decrease due to the build up of an air voidage below the tubes and finally the passing of the large air bubble. This can be seen in the contour plots in Fig. 2. By $0.5 \mathrm{~s}$ for the 1-tube simulation the bubble has completely passed the tube resulting in a sharp increase in the average heat transfer coefficient. As the number of tubes increases there is a delay in the increase in average heat transfer coefficient. This is also seen in Fig. 2 as the bubbles ascend in the bed later with each increasing number of tubes.
The results for the three reactors using the Hill-Koch-Ladd drag model are displayed in Fig. 10. As with the Gidaspow model the first $0.5 \mathrm{~s}$ show the decrease in average heat transfer coefficient as the air voidages form below the tubes and both models show similar behaviour within the period. After $0.5 \mathrm{~s}$, the heat transfer coefficients increase similar to the Gidaspow model results. In both models the heat transfer coefficient is much higher for the single immersed tube. With the Gidaspow model the average heat transfer coefficient decreases with increasing the number of tubes. The average heat transfer of the 3-tube simulation is much lower than the 1-tube and 2-tube simulations for both the Gidaspow and Hill-Koch-Ladd model. This could be due to the additional tube being in a lower position directly above the inlet which could be significantly different to the top tubes hence influencing the average heat transfer coefficient.

There are regular fluctuations in the coefficients for both models as the air voidage builds up below the tube then travels around the tube. The Hill-Koch-Ladd model shows a stronger fluctuation in heat transfer coefficient for the single and triple immersed tube reactors indicating the model's sensitivity to the presence of excess air. However, the Hill-Koch-Ladd model for the dual immersed reactor shows a more smooth average heat transfer coefficient probably due to the positioning of the tubes not situated directly above the fast air inlet. This means the fast flow can travel between the tubes instead of being obstructed and having to travel round the tube which would result in fluctuations of dense and dilute

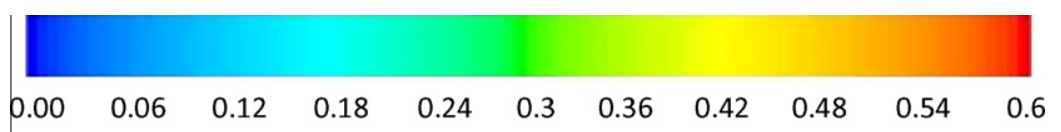

Gidaspow model

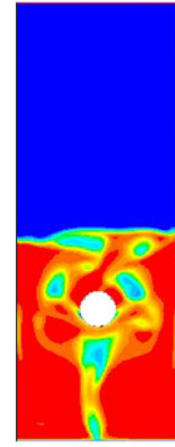

$2.0 \mathrm{~s}$

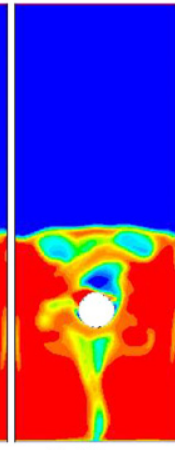

$2.25 \mathrm{~s}$

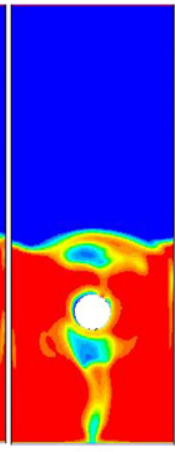

$2.5 \mathrm{~s}$

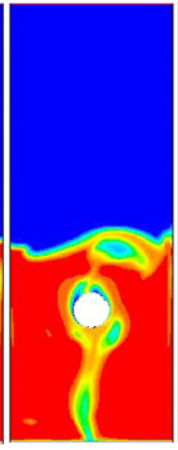

$2.75 s$

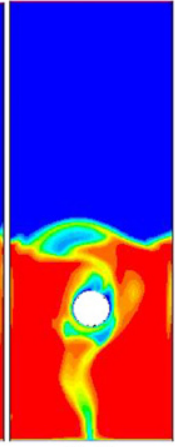

3.0s

Hill-Koch-Ladd model

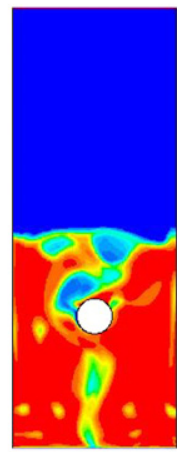

$2.0 \mathrm{~s}$

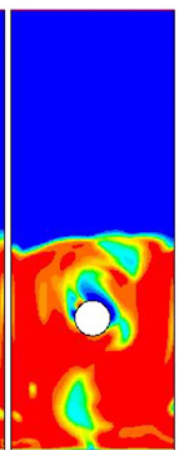

$2.25 \mathrm{~s}$

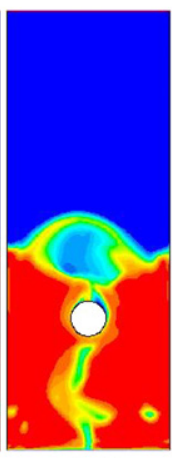

$2.5 \mathrm{~s}$

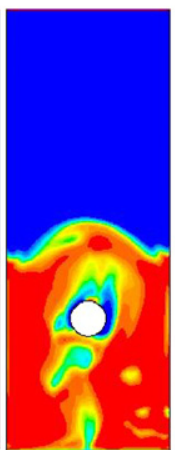

$2.75 s$

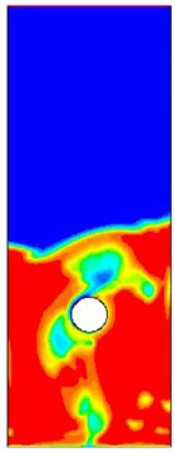

3.0s

Fig. 11. Contour plots of the particle volume fractions for the 1-tube simulation over the $2.0-3.0$ s period using the Gidaspow and Hill-Koch-Ladd drag model. 


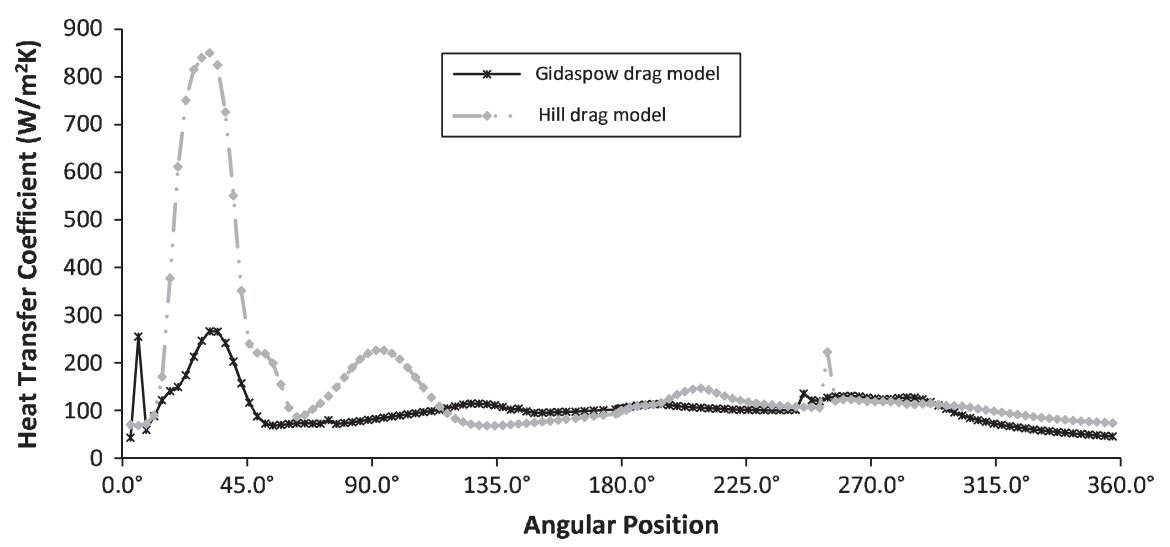

Fig. 12. Local heat transfer coefficient around the tube for the 1-tube model for both drag models at $3.0 \mathrm{~s}$.

regions. The Gidaspow model however picks up more fluctuations than the Hill-Koch-Ladd drag model.

The frequency of the fluctuations for the 1-tube simulation appear to be approximately four cycles in every $0.5 \mathrm{~s}$ for the Gidaspow model whereas the Hill-Koch-Ladd model has approximately three cycles in every $0.5 \mathrm{~s}$. By looking at the volume fraction distribution between the two drag models in Fig. 5 the Hill-Koch-Ladd model shows a higher volume fraction of particles covering the $\approx 0-45^{\circ}$ area of the tube compared to the Gidaspow model which only covers $\approx 0-22^{\circ}$. This larger particle contact area at $0.3 \mathrm{~s}$ could suggest that the model is delaying the release of the bubble from the tube or that the bubble does not blanket around as much of the tube as the other Gidaspow model. However, this would explain the different frequency as the bubbles could be released less regularly and the slightly higher magnitude in the average heat

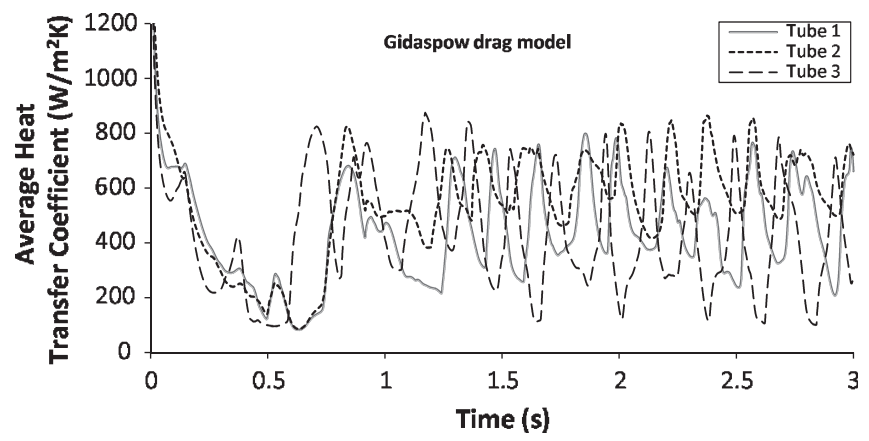

Fig. 13. The average heat transfer coefficients from the individual tubes in the 3 tubes simulation with the Gidaspow drag model over a period of $3.0 \mathrm{~s}$.

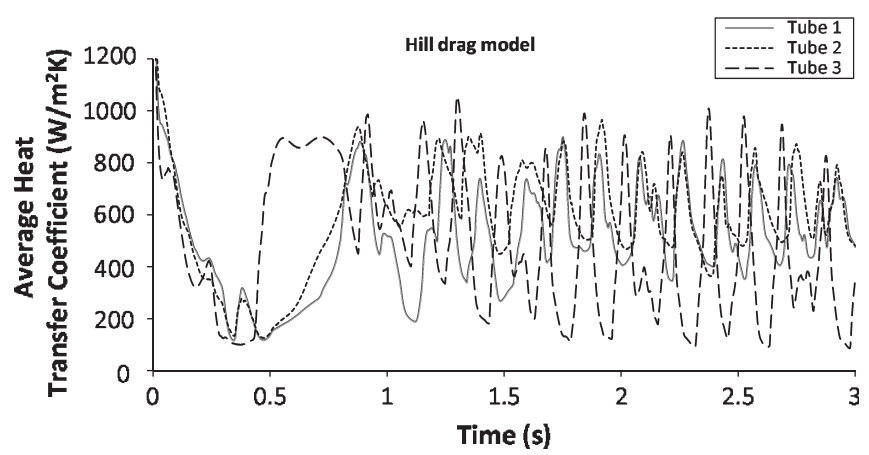

Fig. 14. The average heat transfer coefficients from the individual tubes in the 3 tubes simulation with the Hill-Koch-Ladd drag model over a period of $3.0 \mathrm{~s}$. transfer coefficient due to a larger area of particle contact with the wall.

For the single immersed tube both the Gidaspow and the HillKoch-Ladd models show a significant drop in the average heat transfer coefficient after $2.0 \mathrm{~s}$. This could be due to the collection of air which forms above the tube and appears to remains as seen in Fig. 11. Fig. 12 shows the local heat transfer coefficient around the tube for the 1-tube model for both drag models at $3.0 \mathrm{~s}$. The repositioning of the bubble above the tube shows the maximum heat transfer is reduced to approximately $\approx 280 \mathrm{~W} / \mathrm{m}^{2} \mathrm{~K}$ for the Gidaspow drag model and $\approx 850 \mathrm{~W} / \mathrm{m}^{2} \mathrm{~K}$ for the Hill-Koch-Ladd drag model. Furthermore, the maximum heat transfer coefficient appears to have moved round the tube to around $45^{\circ}$ since the bubble above the tube leads to lower heat transfer above the tube. The value given by the Gidaspow model agrees very well with the calculated maximum heat transfer coefficient from a tube determined by applying the correlation by Zabrodsky (1958) who proposed:

$\alpha_{t_{\max }}=35.7 \kappa_{g}^{0.6} d_{s}^{-0.36} \rho_{s}^{0.2}=296.466 \mathrm{~W} / \mathrm{m}^{2} \mathrm{~K}$

Since the particle contact with the tubes in the 2-tube simulation does not appear to change dramatically as seen in Fig. 4 and the continuous production of the smaller voidages in the 3-tube simulation, the heat transfer coefficient remains generally the same magnitude. After $2.0 \mathrm{~s}$ the average heat transfer coefficient for both models in the three reactors show a similar heat transfer coefficient of approximately $500-600 \mathrm{~W} / \mathrm{m}^{2} \mathrm{~K}$.
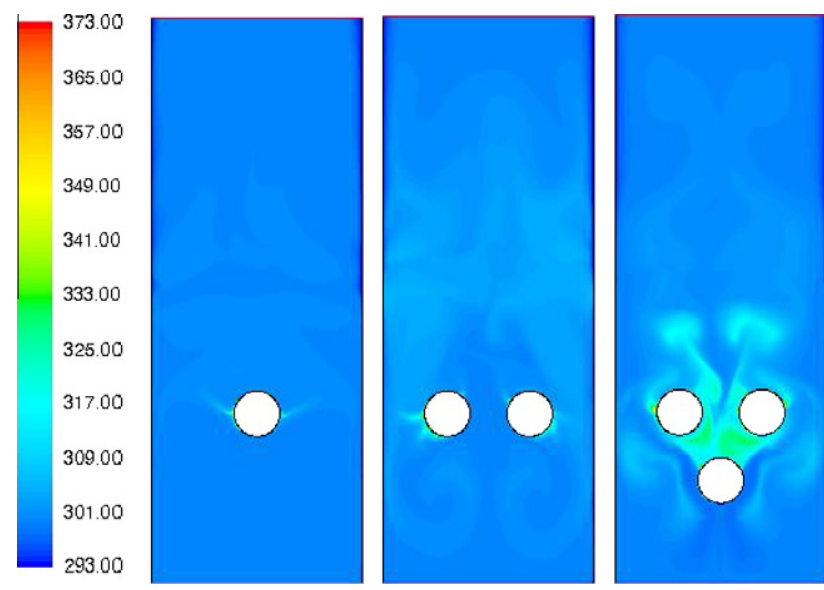

Fig. 15. Contour plots of the particle temperature distribution within the three reactors at $1.0 \mathrm{~s}$ using the Gidaspow drag model. 
The average heat transfer coefficients from the individual tubes in the 3-tube simulation over a $3.0 \mathrm{~s}$ period are displayed for both the Gidaspow and Hill-Koch-Ladd drag models in Figs. 13 and 14, respectively. The first $1.0 \mathrm{~s}$ show a decline on all three tubes as the air pockets gradually build up below each tube therefore reducing the average heat transfer coefficient. With both drag models, tube 3 starts to increase in heat transfer coefficient before tube 1 and tube 2 as the bubbles break away from tube 3 resulting in more particle-wall contact. The average heat transfer coefficients from tube 1 and tube 2 are similar in frequency and wave amplitude due to their positions. However, there are small differences between results of tubes 1 and 2, despite their symmetric positions, confirming that the bed dynamics are not completely symmetric.

After $1.0 \mathrm{~s}$, fluctuations settle into a regular pattern as the gasparticle flow mixes and regulates. The average heat transfer coefficient from tube 3 shows a stronger drop in heat transfer coefficient compared to the other two tubes due to its position directly above the fast air inlet collecting air around the tube hence suppressing the heat transfer. This explains the previous assumption in Section 3.3 for the lower average heat transfer coefficient from the 3-tubes simulation shown in Figs. 9 and 10. During this period of low heat transfer from tube 3 , there is an increase of average heat transfer
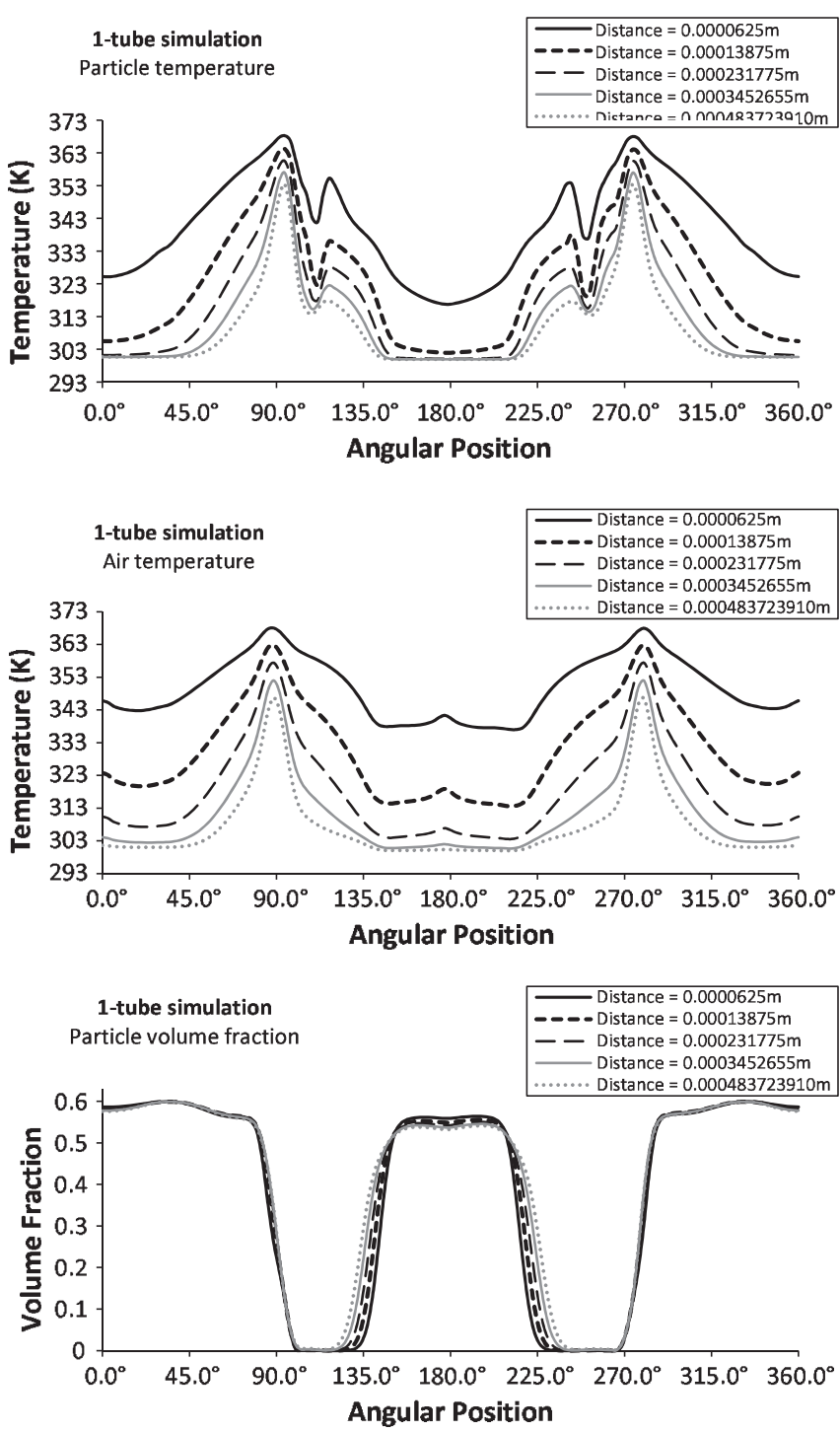

Fig. 16. The local temperature particle temperature, air temperature and particle volume fraction at the five distances from the tube in the 1-tube simulation with the Gidaspow drag model over a period of $1.0 \mathrm{~s}$. from the other two tubes. Once the air voids around tube 3 increase sufficiently, the bubble moves around the tube and ascends towards tubes 1 and 2 resulting in a decrease in average heat transfer from those and an increase from tube 3 as the particles occupy the spaces left by the voidages.

\subsection{Temperature distributions}

Fig. 15 displays the contour plots of the particle temperature distributions at $1.0 \mathrm{~s}$ for a reactor with one, two and three immersed tubes using the Gidaspow drag model. After $1.0 \mathrm{~s}$ there is a clear indication that more immersed tubes increases the temperature of the particles within the bed due to an increase in the heat transfer area. The higher temperatures are observed in the presence of dilute regions as the active particles travel from the heated walls through the voids. In the 3-tube simulation, the increase in the number of heated tubes along with the presence of more smaller particle carrying voidages results in a much higher temperature of particles compared to the other two reactors. The temperature distribution within the double tube reactor clearly shows the circulation of particles carrying higher temperatures.
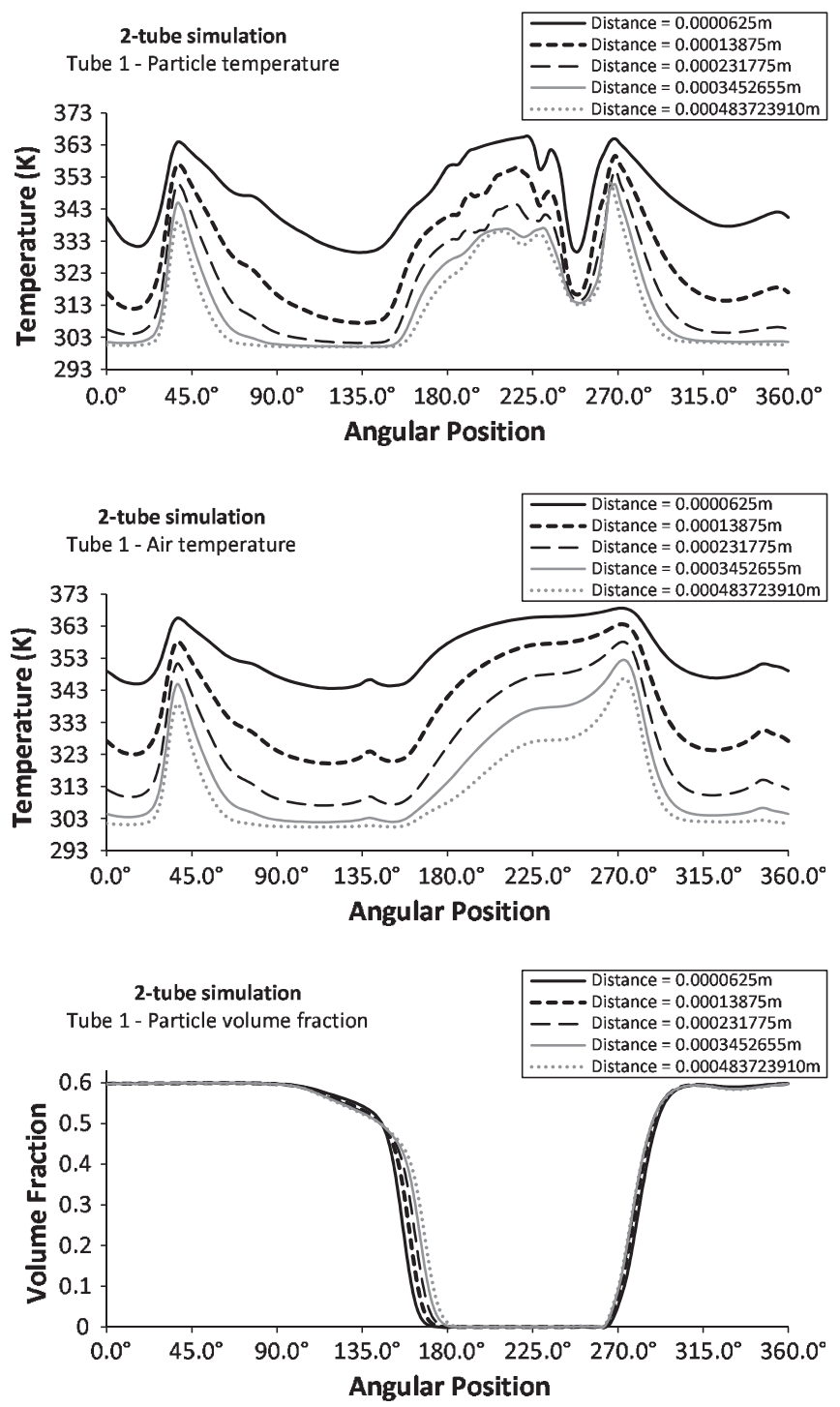

Fig. 17. The local temperature particle temperature, air temperature and particle volume fraction at the five distances from tube 1 in the 2-tube simulation with the Gidaspow drag model over a period of $1.0 \mathrm{~s}$. 
The contour plot in Fig. 15 at 1.0 does not display the different temperatures in the near region of the tubes. The results are expanded in Figs. 16-18 to display the particle and air temperature at $1.0 \mathrm{~s}$ at the five different distances from the tubes (given in Fig. 1c) for the 1-, 2- and 3-tube simulation. Fig. 16 display the local results for the 1-tube simulation. A clear observation is that the particle and air temperatures are higher closer to the tubes as expected. As the distance from the tube increases the temperature increase reduces until in there appears to be no change from the bed temperature of $293 \mathrm{~K}$. The local temperature of the air however appears to be slightly higher than that of the particles. This could be due to the air voidages between compact particles and the tube being influenced by not only the heat from the tube but also the heat from the local particles. The local particle volume fraction is also shown in Fig. 16. The peak temperatures for both particles and air can be seen during the transitions from dense to dilute regions. This will be due to the increased movement of particles in the vicinity of the tube as the air moves the particles away from the wall. This mixing allows heated particles to travel and be replaced with cooler particles. These mixing heated particles then carry the heat to the local regions. At $135^{\circ}$, the volume fraction
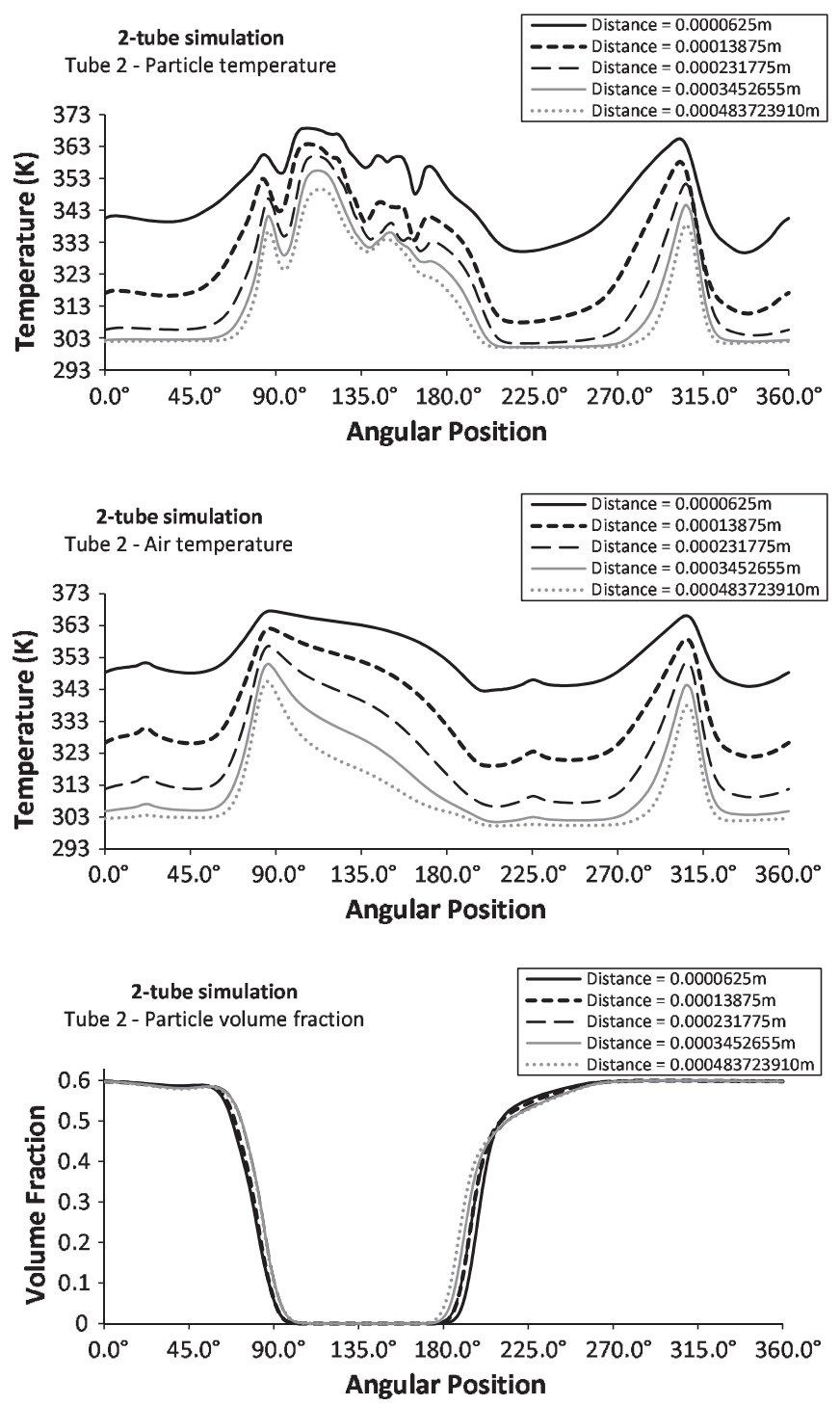

Fig. 18. The local temperature particle temperature, air temperature and particle volume fraction at the five distances from tube 2 in the 2-tube simulation with the Gidaspow drag model over a period of $1.0 \mathrm{~s}$. results show a transition from dilute to dense conditions however instead of an increased particle temperature there is a reduction. This would be due to the re-introduction of cooler particles against the wall as it occurs directly below the tubes above the fast air inlet which will be forcing cooler particles against the lower regions of the tube.

Figs. 17 and 18 display the local particle, air and volume fraction results for tube 1 and tube 2 in the 2-tube simulation respectively. As seen for the 1-tube simulation results in Fig. 16 the temperature of the particles and air is higher closer to the heated tube. Also the results show a relatively symmetrical distribution for the temperatures and volume fractions due to the symmetrical positioning of the tubes. The results also show higher temperatures in the regions where the mixture is dilute and sufficient mixing is taking place. It can also be seen at approximately $45^{\circ}$ on tube 1 and $315^{\circ}$ on tube 2 that there is a significant peak in the temperature of both the particles and the air whereas there is a very dense region of particles. This was not observed with the 1-tube simulation. It can be seen in Fig. 2 that the trajectory of the air bubbles appear to be around the outside of the two tubes in the 2-tube simulation so the compacted particles against the wall at approximately $45^{\circ}$ on tube 1 and $315^{\circ}$
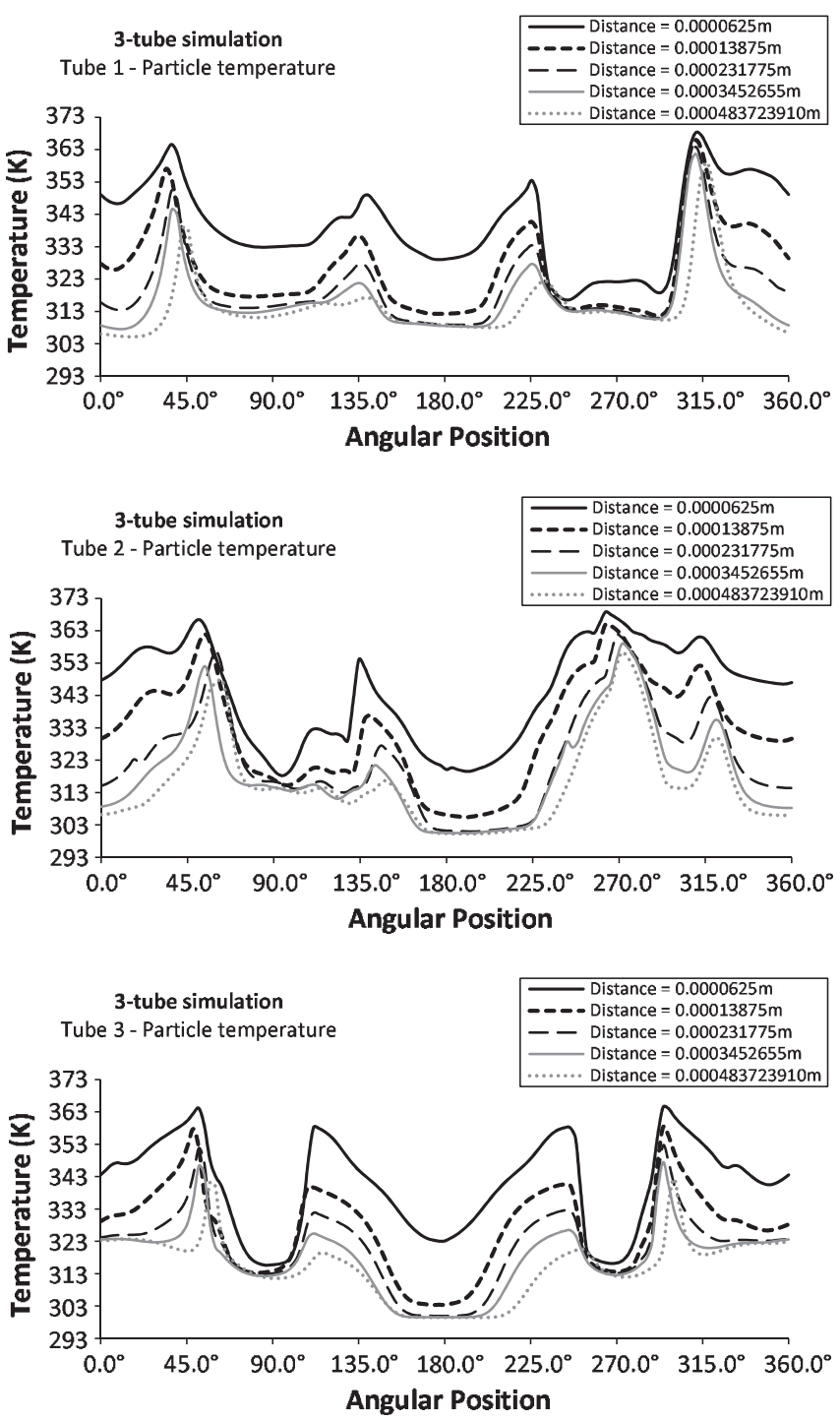

Fig. 19. The local temperature particle temperature at the five distances from the tube in the 3-tube simulation with the Gidaspow drag model over a period of $1.0 \mathrm{~s}$. 
on tube 2 do not mix well. Therefore the increased residence time against the wall increases the temperature significantly.

The particle temperature and volume fraction at the different distances from the tubes in the 3-tube simulation at $1.0 \mathrm{~s}$ are given in Figs. 19 and 20, respectively. The third tube shows a general symmetrical distribution for both the temperature and particle volume fraction results whereas tube 1 and tube 2 shows significant asymmetry from both tube 3 and each other. This is because increasing the tubes lead to the break up of larger bubbles into smaller ones particularly between the three tubes. Resulting in increased mixing which would produce an unpredictable distribution of particles within the vicinity of the tubes. As seen in the previous reactors and as expected the temperature is highest closer to the heated tube. However, compared with the results from the 1-tube and 2-tube simulations the results for the furthest distances from all three tubes show a overall increase in particle temperature. This is again a result of the increased mixing between the tubes and is explained further with the volume fraction results in Fig. 20 where other than the tops of the tubes (approx 315-45 ${ }^{\circ}$ ) there are very few dense particle regions indicating particles can move more freely distributing the heat more.
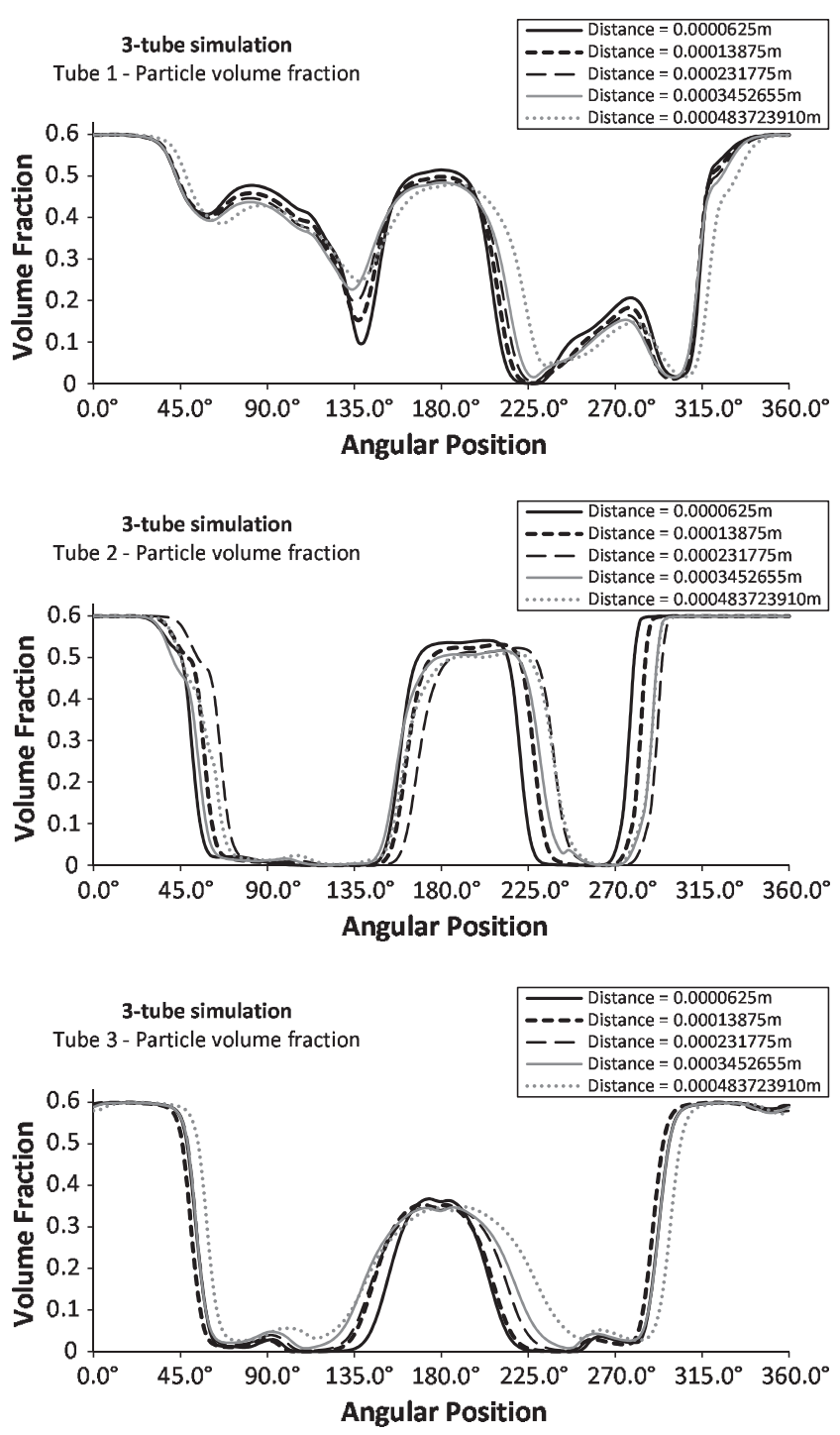

Fig. 20. The local particle volume fraction at the five distances from each of the tubes in the 3-tube simulation using the Gidaspow drag model over a period of $1.0 \mathrm{~s}$.

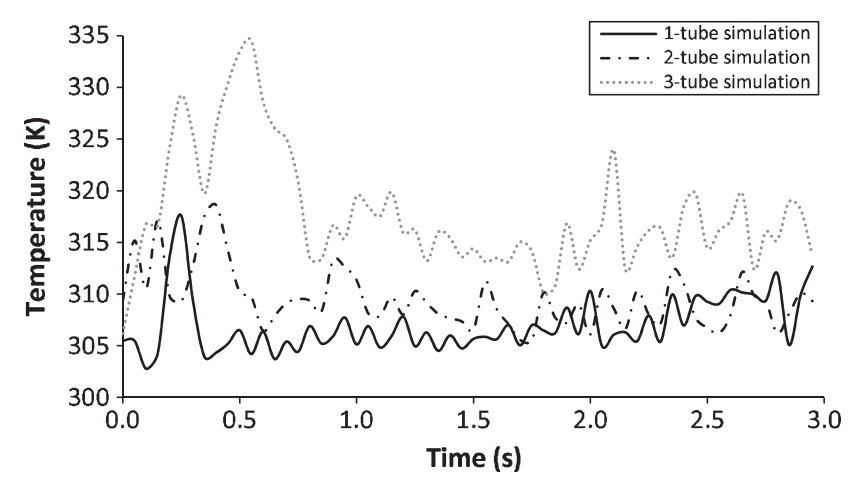

Fig. 21. Instantaneous collective average particle temperature from all the tubes in the 1-, 2- and 3-tube simulations at a distance of $0.000483723910 \mathrm{~m}$ from the tube over a period of $3.0 \mathrm{~s}$ with the Gidaspow drag model.

In order to display the effect of varying particle volume fractions in the near-tube regions with varying time the results in Fig. 21 show the instantaneous average particle temperature collectively taken from all the tubes in the 1-, 2- and 3-tube simulations from the furthest distance of $0.000483723910 \mathrm{~m}$ from the tubes over a period of $3.0 \mathrm{~s}$ with the Gidaspow drag model. The initial $0.75 \mathrm{~s}$ indicate the simulations forming a regular pattern as the gas-particle flow mixes and regulates. The average temperature from all the tubes in the 3-tube reactor is significantly higher than those of the other two reactors agreeing with the instantaneous results at $1.0 \mathrm{~s}$ in Fig. 19. It can also be seen that the results of the 2-tube simulation show a slight increase over the results of the 1-tube model. This would confirm that increasing the number of tubes would increase the temperature in the reactor faster. However since these results are only in the near-tube region of the tubes where the temperature from the other tubes would not directly influence these results it could also indicate that improved mixing within the near-tube regions have a significant influence on temperature distribution.

\section{Conclusion}

Three tube-to-bed heated fluidised bed reactors have been modelled using an Eulerian-Eulerian kinetic theory of granular flow model. A reactor containing one immersed tube was set up based on a model from the literature (Schmidt and Renz, 1999) and compared with their predicted results. The models looked at the flow characteristics and local heat transfer coefficients using multiple drag models including the Hill-Koch-Ladd drag model derived from kinetic theory. The flow characteristics showed a close resemblance to the symmetrical results in literature. Increasing the number of tubes improved the heat transfer into the bed due to the increased heat transfer area and the break up of bubbles to form smaller particle carrying voidages. Moreover, extending the simulation time from the previously carried out $0.45-3.0 \mathrm{~s}$ shows an increasingly asymmetric distribution. The local heat transfer coefficients for all the drag models agreed reasonably well with the results obtained in the literature for an effective thermal conductivity consisting of only a molecular contribution. The results from the kinetic contribution greatly overestimated the values of the heat transfer coefficients due to the strong influence that the granular temperature has on the kinetic theory of granular flow. The local volume fraction distribution varied greatly from the predicted results observed in the literature yet the present timeaveraged particle volume fraction results followed the expected trend determined experimentally (Di Natale et al., 2010), thus confirming that the previous assumption made in the literature (Schmidt and Renz, 1999) to use a symmetric bed would not 
correctly capture the correct flow dynamics. The average heat transfer coefficient extracted from the circumference of the tube for the three models were taken and plotted over a $3.0 \mathrm{~s}$ period for the standard Gidaspow drag model and the modified HillKoch-Ladd drag model. The results showed that the Gidaspow model detected the passage of the bubble around the tube before the Hill-Koch-Ladd model however their average heat transfer coefficient values were of similar magnitude. Furthermore, for multiple immersed tubes the average heat transfer coefficient differed in magnitude for each tube, again confirming the asymmetric flow distribution and the effect of tube positioning. A contour plot for the temperature distribution of the particles showed that increasing the number of tubes increases heat transfer from the tubes to the particles and the flow around the tubes resulting in increased temperature. The local particle temperature and particle volume fractions at different distances from the tube were analysed for the three reactors and found that increased particle temperature occurred in the transition from dense particle-laden regions to dilute region as the particles experience mixing. The transition from dilute to dense particle regions resulted in local temperature reduction as new cooler particles are introduced to the vicinity. The instantaneous average particle temperature for the three reactors showed that increasing the number tubes resulted in an increase in the local particle temperature were improved mixing was shown to be a contribution.

\section{References}

Almuttahar, A., Taghipour, F., 2008. Computational fluid dynamics of high density circulating fluidized bed riser: study of modeling parameters. Powder Technol. 185, 11-23.

Arastoopour, H., Pakdel, P., Adewumi, M., 1990. Hydrodynamic analysis of dilute gas-solids flow in a vertical pipe. Powder Technol. 62, 163-170.

Armstrong, L.M., Luo, K., Gu, S., 2009. Three-dimensional modelling on the hydrodynamics of a circulating fluidised bed. In: Proceedings of the Inaugural US-EU-China Thermophysics Conference, Beijing, China.

Armstrong, L.M., Luo, K., Gu, S., 2010a. Two-dimensional and three-dimensional computational studies of hydrodynamics in the transition from bubbling to circulating fluidised bed. Chem. Eng. J. 160, 239-248.

Armstrong, L.M., Luo, K., Gu, S., 2010b. CFD modelling of the gasification of coal particles in fluidised beds. In: Proceedings of the International Heat Transfer Conference, Washington, DC, USA.

Armstrong, L.M., Gu, S., Luo, K., 2010c. Study of wall-to-bed heat transfer in a bubbling fluidised bed using the kinetic theory of granular flow. Int. J. Heat Mass Transfer 53, 4949-4959.

Benyahia, S., Arastoopour, H., Knowlton, T., Massah, H., 2000. Simulation of particles and gas flow behaviour in the riser section of a circulating fluidized bed using the kinetic theory approach for the particulate phase. Powder Technol. 112, 24-33.

Benyahia, S., Syamlal, M., O'Brien, T., 2006. Extension of Hill-Koch-Ladd drag correlation over all ranges of reynolds number and solids volume fraction. Powder Technol. 162, 166-174.

Berruti, F., Chaouki, J., Godfroy, L., Pugsley, T., Patience, G., 1995. Hydrodynamics of circulating fluidized bed risers: a review. Can. J. Chem. Eng. 73, 579-602.

Chapman, S., Cowling, T., 1970. The Mathematical Theory of Non-Uniform Gases, third ed. Cambridge University Press, Cambridge, UK.

Di Felice, R., 1994. The voidage functions for fluid-particle interaction systems. Int. J. Multiphase Flow 20, 153-159.

Di Natale, F., Bareschino, P., Nigro, R., 2010. Heat transfer and void fraction profiles around a horizontal cylinder immersed in a bubbling fluidised bed. Int. J. Heat Mass Transfer 53, 3525-3532.

Ergun, S., 1952. Fluid flow through packed columns. Chem. Eng. Prog. 48, 89-94.

Ge, W., Li, J., 1997. Pseudo-particle approach to hydrodynamics of gas/solid twophase flow. In: Proceedings of the 5th International Conference on Circulating Fluidized Beds. Science Press, Beijing, pp. 260-265.

Ge, W., Li, J., 2001. Macro-scale pseudo-particle modeling for particle-fluid systems. Chin. Sci. Bull. 46, 1503-1507.

Ge, W., Li, J., 2003. Macroscale phenomena reproduced in microscopic systemspseudo-particle modeling of fluidization. Chem. Eng. Sci. 58, 1565-1585.

Gera, D., Gautam, M., Tsuji, Y., Kawaguchi, T., Tanaka, T., 1998. Computer simulation of bubbles in large-particle fluidized beds. Powder Technol. 98, 38-47.

Gera, D., Syamlal, M., O'Brien, T., 2004. Hydrodynamics of particle segregation in fluidized beds. Int. J. Multiphase Flow 30, 419-428.

Gidaspow, D., 1994. Multiphase Flow and Fluidization, Continuum and Kinetic Theory Descriptions. Academic Press, Inc.
Gidaspow, D., Bezburuah, R., Ding, J., 1992. Hydrodynamics of circulating fluidized beds: kinetic theory approach. In: Proceedings of the 7th Fluidization Conference.

Goldschmidt, M., Kuipers, J., van Swaaij, W., 2001. Hydrodynamic modelling of dense gas-fluidized beds using the kinetic theory of granular flow: effect of restitution coefficient on bed dynamics. Chem. Eng. Sci. 56, 571.

Gunn, D., 1978. Transfer of heat or mass to particles in fixed and fluidised beds. Int. J. Heat Mass Transfer 21, 467-476.

Hill, R., Koch, D., Ladd, A., 2001a. The first effects of fluid inertia on flows in ordered and random arrays of spheres. J. Fluid Mech. 448, 213-241.

Hill, R., Koch, D., Ladd, A., 2001b. Moderate-Reynolds-number flows in ordered and random arrays of spheres. J. Fluid Mech. 448, 243-278.

Hunt, M., 1997. Discrete element simulations for granular material flows: effective thermal conductivity and self diffusivity. Int. J. Heat Mass Transfer 40, 30593068.

Ibsen, C., Helland, E., Hjertager, B., Solberg, T., Tadrist, L., Occelli, R., 2004. Comparison of multifluid and discrete particle modelling in numerical predictions of gas particle flow in circulating fluidised beds. Powder Technol. 149, 29-41.

Kuipers, J., Prins, W., van Swaaij, W., 1992. Numerical calculation of wall-to-bed heat transfer coefficients in gas-fluidized beds. AIChE J. 38, 1079-1091.

Lun, C., Savage, S., Jeffrey, D., Chepurniy, N., 1984. Kinetic theories for granular flow: inelastic particles in Couette flow and slightly inelastic particles in a general flow field. J. Fluid Mech. 140, 223-256.

Natarajan, V., Hunt, M., 1998. Kinetic theory analysis of heat transfer in granular flows. Int. J. Heat Mass Transfer 41, 1929-1944.

Papadikis, K., Bridgwater, A., Gu, S., 2008. CFD modelling of the fast pyrolysis of biomass in fluidised bed reactors, part a: Eulerian computation of momentum transport in bubbling fluidised beds. Chem. Eng. Sci. 63, 4218-4227.

Papadikis, K., Bridgwater, A., Gu, S., 2010a. A CFD approach on the effect of particle size on char entrainment in bubbling fluidised bed reactors. Biomass Bioenergy $34,21-29$.

Papadikis, K., Gerhauser, H., Bridgwater, A., Gu, S., 2009a. CFD modelling of the fast pyrolysis of an in-flight cellulosic particle subjected to convective heat transfer. Biomass Bioenergy 33, 97-107.

Papadikis, K., Gu, S., Bridgwater, A., 2009b. CFD modelling of the fast pyrolysis of biomass in fluidised bed reactors: modelling the impact of biomass shrinkage. Chem. Eng. J. 149, 417-427.

Papadikis, K., Gu, S., Bridgwater, A., 2009c. CFD modelling of the fast pyrolysis of biomass in fluidised bed reactors. Part b: heat, momentum and mass transport in bubbling fluidised beds. Chem. Eng. Sci. 64, 1036-1045.

Papadikis, K., Gu, S., Bridgwater, A., 2010b. 3d simulation of the effects of sphericity on char entrainment in fluidised beds. Fuel Process. Technol. 91, 749-758.

Papadikis, K., Gu, S., Bridgwater, A., 2010c. Computational modelling of the impact of particle size to the heat transfer coefficient between biomass particles and a fluidised bed. Fuel Process. Technol. 91, 68-79.

Papadikis, K., Gu, S., Bridgwater, A., Gerhauser, H., 2009d. Application of CFD to model fast pyrolysis of biomass. Fuel Process. Technol. 90, 504-512.

Papadikis, K., Gu, S., Fivga, A., Bridgwater, A., 2010d. Numerical comparison of the drag models of granular flows applied to the fast pyrolysis of biomass. Energy Fuels 24, 2133-2145.

Patil, D., Smit, J., van Sint Annaland, M., Kuipers, J., 2006. Wall-to-bed heat transfer in gas-solid bubbling fluidized beds. AIChE J. 52, 58-74.

Samuelsberg, A., Hjertager, B., 1995. An experimental and numerical study of flow patterns in a circulating fluidized bed reactor. Int. J. Multiphase Flow 22, 575591.

Schaeffer, D., 1987. Instability in the evolution equations describing incompressible granular flow. J. Differen. Equat. 66, 19-50.

Schmidt, A., Renz, U., 1999. Eulerian computation of heat transfer in fluidized beds. Chem. Eng. Sci. 54, 5515-5522.

Schmidt, A., Renz, U., 2000. Numerical prediction of heat transfer in fluidized beds by a kinetic theory of granular flows. Int. J. Therm. Sci. 39, 871-885.

Sinclair, J., Jackson, R., 1989. Gas-particle flow in a vertical pipe with particleparticle interactions. AIChE J. 35, 1473.

Sundaresan, S., 2000. Perspective: modeling the hydrodynamics of multiphase flow reactors: current status and challenges. AIChE J. 46, 1102-1105.

Syamlal, M., Gidaspow, D., 1985. Hydrodynamics of fluidization: prediction of wallto-bed heat transfer coefficients. AIChE J. 31, 127-135.

Syamlal, M., O'Brien, T., 1987. Derivation of a drag coefficient from velocity-voidage correlation. In: U.S. Dept. of Energy, Office of Fossil Energy, National Energy Technology Laboratory, Morgantown, West Virginia, April.

Taghipour, F., Ellis, N., Wong, C., 2005. Experimental and computational study of gas-solid fluidized bed hydrodynamics. Chem. Eng. Sci. 60, 6857-6867.

Vasquez, S., Ivanov, V., 2000. A phase coupled method for solving multiphase problems on unstructured meshes. In: Proceedings of ASME FEDSM'00: ASME 2000 Fluids Engineering Division Summer Meeting, Boston.

Wen, Y., Yu, Y., 1966. Mechanics of fluidization. Chem. Eng. Prog. Symp. Ser. 62, 100.

Zabrodsky, S., 1958. Analysis of experimental data on heat transfer in fluidized beds. Inzh.-Fiz. Zhurn. 1, 22-30 (in Russian).

Zehner, P., Schlünder, E., 1970. Wärmeleitfähigkeit von schüttungen bei mä $\beta$ igen temperaturen. Chem. Ing. Tech. 42, 933-941. 